\title{
LA VÍA CHILENA AL SOCIALISMO ${ }^{1}$
}

La Via Chilena al Socialismo es el libro del plan del "Gobierno Popular de Chile", impreso en los Talleres del Servicio de Prisiones en 1971. Inicia con un discurso del presidente Salvador Allende que en el ejemplar del Archivo Central Andrés Bello no se encuentra. El libro fue catalogado como "La política de Gobierno", que es la primera parte del plan, y hoja inicial de este volumen que perteneció a Eliana Dobry Cohan, profesora de la Facultad de Filosofía y Educación exiliada en Londres y cuya biblioteca llega por donación de sus hijos en 1993. Se trata de una biblioteca personal y familiar que sobrevivió a la represión de la dictadura y se mantuvo oculta por más de treinta años. La falta de páginas iniciales pudo obedecer a la estrategia de protección de sus libros, pues a otros les pintó o arrancó las portadas, en particular aquellos que en su título decían marxismo o socialismo. Se seleccionan las páginas iniciales que describen la "política de nuevo estilo" y los apartados sobre educación y salud pública de la política social, por su pertinencia para el debate actual sobre derechos sociales en una nueva Constitución para Chile. La política de nuevo estilo tenía como ejes una voluntad de servicio, aceleración de los cambios y centralidad de las bases populares y juveniles como motores de un nuevo país.

1. Política de gobierno (1971). En La vía chilena al socialismo. Talleres Gráficos del Servicio de Prisiones: Colección General Donación Eliana Dobry, Archivo Central Andrés Bello, Universidad de Chile, pp. 3-7, 539-578. 


\section{1.- UNA POLITICA DE NUEVO ESTILO}

El Gohierno Popular de Chile, representa una experiencia histórica, con un profundo contenido que rebasa, incluso, nuestra realidad nacional.

Con la presencia real de los trabajadores en el Gobierno, se ha inaugurado un nuevo estilo de política, que responde a los genuinos intereses de Chile y su pueblo.

Múltiples manifestaciones de esta nueva concepción pueden encontrarse en los primeros seis meses de esta administración.

\section{TRASLADO DEL GOBIERNO A VALPARAISO:}

Uno de los males que han repercutido en términos altamente desfavorables para el desarrollo del país, ha sido el excesivo centralismo con que, tradicionalmente, se han enfrentado las labores políticas y administrativas del Gobierno.

Preocupación preferente del actual Gobierno, ha sido romper con esta práctica y obtener así un adecuado desarrollo de las potencialidades de las distintas regiones de nuestro territorio.

Consecuente con esta política, el Compañero Presidente determinó que la sede del Gobierno se trasladara a la provincia de Valparaíso; la Secretaría General de Gobierno tuvo a su cargo la responsabilidad de organizar esta forma de trabajo y con un reducido grupo de funciorios, encaró las exigencias que planteó esta nueva modalidad.

Cabe destacar que en esta oportunidad se contó con la colaboración ejemplar de todos los que concurrieron a cumplir con esta tarea. Así, el total de los funcionarios que debieron cambiar el lugar habitual de su residencia, no percibieron viáticos, ni forma alguna de asignación extraordinaria. El alojamiento y la alimentación fueron proporcionados por la Dirección General de Carabineros, habilitando para estos efectos el casino que tienen en la ciudad de Valparaíso. El mobiliario de las oficinas fue aportado por diversos servicios públicos, evitando de este modo, gastos en este rubro.

La Oficina de Planificación Nacional de la Presidencia de la República, destacó un equipo de técnicos de alta calificación para realizar un acabado estudio de los problemas de la zona.

El plan fue elaborado no como un informe técnico más, en los cuales las mediciones no reflejan, muchas veces, la pujante realidad que se encuentra bajo ellos, sino en una discusión seria y un análisis responsable hecho con todos los sectores sociales vinculados a la región.

Por otra parte, se creó la Oficina Regional de Planificación para Valparaíso y Acoricagua (ORPLAN) que continuará adelante en el estudio y evaluación de las labores programadas. 
Párrafo aparte merece el traslado definitivo del Ministerio de Tierras y Colonización a nuestro primer puerto. En efecto, la necesidad de atender preferentemente nuestra gran riqueza marítima, determinó la elaboración y aprobación, en los organismos técnicos del Ejecutivo, del proyecto que convierte a dicho Ministerio, en el Ministerio del Mar, sobre características y funciones se hace un análisis particular en el capítulo correspondiente del Mensaje.

En los 40 días de permanencia del Gobierno en Valparaíso, el Presidente de la República y la Secretaría General de Gobierno, pusieron en práctica una forma distinta de concebir la conducción del país, haciendo conciencia en toda la comunidad de su derecho y su deber de participar, de manera activa, en la solución de sus propios problemas.

En la práctica, esto se tradujo en un contacto permanente con los pobladores, juntas de vecinos, cooperativas, sindicatos, grupos industriales y profesionales, en fin, con la más amplia gama de sectores sociales, con los cuales se mantuvo un fructífero diálogo y con cuyjo concurso se abordó la solución de múltiples problemas.

En el terreno mismo se planteó la solución a variados requerimientos, con visitas diarias a poblaciones, sindicatos en conflicto, cooperativas de construcción, etc. Ministros de Estado, Subsecretarios y altos funcionarios de Gobierno sostuvieron innumerables reuniones con los trabajadores, las que se tradujeron en medidas de beneficio colectivo.

Paralelamente se desarroló una amplia labor de fiscalización de la actividad de los Servicios Públicos, empapándolos en las ideas planteadas por el Compañero Presidente en la conversación que sostuvo con los Jefes de Servicio a poco tiempo de asumir el Mando. No escapa a nadie que el criterio de este Gobierno es que cada funcionario público tiene una obligación moral que cumplir que va más allá de sus obligaciones formales. Debe redoblar su eficiencia, su espíritu de sacrificio, su actitud de servicio a la comunidad, y quien no lo entienda así, no tiene cabida en esta tarea que, como se ha dicho en muchas oportunidades, no es la tarea de un hombre o un gobierno, sino la tarea del pueblo.

La experiencia de Valparaíso ha demostrado que es posible agilizar la labor de Gobierno con la dedicación, la creatividad y el sacrificio de los funcionarios y de la comunidad; ha puesto al descubierto los males y las deficiencias estructurales del aparato burocrático que provocan dilaciones y tramitaciones innecesarias; ha demostrado, en fin, la urgencia de dotar a las autoridades provinciales de mayores atribuciones para resolver los asuntos de sus regiones, con la celeridad que ellos requieren.

Pero, por encima de estas consideraciones hay un hecho que adquiere una especial dimensión histórica. Por primera vez, el pueblo tiene un amplio cauce para discutir, analizar y adoptar decisiones sobre su futuro. Ya no es el espectador pasivo que soporta las medidas que otros toman o que espera todo de un Estado benefactor. A través de la participación popular, plasmada en el esfuerzo diario del pueblo y su Gobierno, se ha demostrado que es posible alcanzar metas que antes podían calificarse de ilusorias. 
Las jornadas de Discusión Popular, realizadas en Valparaíso, son una muestra elocuente de lo expresado en los párrafos anteriores. Durante dos semanas, con la participación del Departamento de Sociología de la Universidad de Chile, la Consejería de Desarrollo Social y ODEPLAN, se llevaron a cabo estas jornadas en distintos Centros Comunitarios del puerto.

Cada día, un Ministro de Estado, un Subsecretario, un profesor universitario, un parlamentario y otras figuras de alta representatividad, discutieron con los trabajadores sobre la política económica y social que se estaba desarrollando y sus proyecciones futuras. La experiencia no pudo resultar más rica en iniciativas, aportes valiosos y reafirmación de un nuevo concepto sobre la sociedad chilena

\section{OPERACION INVIERNO}

Frente al estado de miseria que se fue acumulando en las poblaciones periféricas durante todos los años anteriores, como consecuencia de un sistema capitalista que no fue capaz de dar una solución so cial y humanitaria a los problemas de la población, el Gobierno de la Unidad Popular definió una tarea de emergencia para mejorar las condiciones en que estas numerosas familias van a pasar el próximo período de lluvias.

Esta tarea se ha denominado "Operación Invierno", y conjuga varios objetivos:

- proporcionar techo y urbanizaciones mínimas a los pobladores en situación irregular;

- cooperar a la absorción de la cesantía; agilizando los programas definidos por el Gobierno, principalmente en Vivienda y Obras Públicas, $\mathrm{y}$

- propender a un control de las inundaciones mediante el trabajo coordinado de las instituciones gubernamentales y las Municipalidades.

Toda esta acción que se indica más adelante, no ha significado atrasar o posponer las metas fijadas para este año, sino movilizar y poner en tensión el aparato estatal, superando la burocracia tradicional y recogiendo la participación de las organizaciones de bases, donde destacan los pobladores, los trabajadores, y la juventud.

El esfuerzo principal ha estado centrado en la Secretaría General de Gobierno, que ha contado con la participación de ODEPLAN, CUT, SENDE, y los organismos del Ministerio de la Vivienda y el Ministerio de Obras Públicas, para conformar un equipo de trabajo multiinstitucional, flexible y eficiente.

44.000 familias se encontraban en Santiago viviendo en campamentos en condiciones muy precarias, $\mathrm{y}$ es en este sentido donde se ha orientado en forma principal la "Operación Invierno".

No es posible pretender en pocos meses superar el déficit de viviendas acumulado. Se está llevando adelante el plan de construcciones más ambicioso de nuestra historia, pero también se ha fijado como 
responsabilidad mejorar las condiciones de las familias que no alcanzarán a tener solución definitiva este año, y aquellas para las cuales se les está construyendo su vivienda definitiva.

Estas soluciones son transitorias y se están realizando frente a las emergencias enunciadas, pero, la diferencia fundamental, está en que este Gobierno se ha preocupado de este fenómeno antes que las desgracias ocurran.

Siempre quedarán necesidades sin satisfacer. Hay problemas acumulados durante muchos años, pero hasta este momento se ha:

- entregado vivienda provisional a 4.520 familias en Santiago, de las 9.430 programadas por los propios pobladores;

- ripiado $109.000 \mathrm{~m}^{2}$ de calles en campamentos;

- atendido a 128 campamentos con agua, luz y letrinas;

- iniciado la construcción de 250 locales escolares transportables, aprovechando buses dados de baja en la E.T.C.;

- superado el problema de basurales en los campamentos, y preparado los terrenos mediante la contratación especial de cuadrillas de trabajadores, el apoyo organizado de los pobladores, y el valioso aporte de la Fuerza Militar del Trabajo;

- realizado una intensa labor de limpieza de canales, sumideros de aguas-lluvias, y construcción de defensas fluviales.

Es necesario destacar que los resultados de este esfuerzo se multiplicaron, y siguen creciendo por la participación de los pobladores organizados, y de los trabajos voluntarios de los obreros, empleados y la juventud.

\section{SECRETARIA GENERAL DE LA JUVENTUD.}

El Gobierno valora especialmente el rol protagónico que cumple la juventud en el proceso histórico que se ha iniciado. No se puede dejar de reconocer el extraordinario aporte que entregó el movimiento juvenil chileno a la conquista de este Gobierno, que es efectivamente representativo de los anhelos de la gran mayoría ciudadana. Esto se debe a que el movimiento juvenil chileno ha venido desde hace muchos años fortaleciendo su organización y acerando su conciencia política en las luchas junto a la clase trabajadora. Todas y cada una de las batallas del pueblo chileno contra las injusticias del sistema capitalista han contado con la presencia generosa y combativa de la juventud chilena.

No se puede olvidar los grandes movimientos juveniles universitarios por transformar la vieja Universidad y ponerla al servicio del desarrollo nacional, por democratizarla poniéndola al alcance de los hijos de los trabajadores. No se puede olvidar tampoco, las grandes jornadas de los jóvenes estudiantes de la Enseñanza Media en pro de más y mejores condiciones de estudio y de generosa solidaridad con sus maestros, campesinos y trabajadores. Así también, la juventud obrera y campesina que es la que ha sufrido con más rigor la injusticia y la explotación ha librado memorables batallas, dando muestras de su alta conciencia política que la ha colocado a la vanguardia de lo que es hoy el movimiento juvenil chileno. 
$\mathrm{Y}$ es precisamente debido a su alta organización, responsabilidad y madurez política que se puede afirmar que entre la juventud chilena y el actual Gobierno, no existe ningún tipo de contradicciones. Las aspiraciones de la juventud, son las aspiraciones del Gobierno popular y es por esto mismo que se puede mirar con plena confianza el futuro de nuestra patria. Cada uno de los anhelos y metas de la juventud contará con el más amplio y decidido apoyo del Gobierno Popular. Construir una nueva sociedad, desarrollar al máximo las enormes potencialidades de nuestro país requiere del concurso de todos, y naturalmente de los jóvenes.

Porque el Gobierno entiende cabalmente su compromiso con toda la juventud chilena se creó en los inicios de esta Administración, la Secretaría General de la Juventud, que tiene la alta misión de vincular los planes del Gobierno con el movimiento juvenil chileno y elaborar una política global que posibilite la integración plena de la juventud a las grandes metas del desarrollo nacional y que permita que cada joven pueda expresar y cristalizar toda su potencialidad creadora. Es por esto que será especial preocupación el área de la educación y la cultura, de la recreación y el deporte, el desarrollo social y económico, y en definitiva el mejoramiento de las condiciones de vida de la juventud chilena.

Esto se corrobora por el extraordinario incremento de la capacidad de las universidades chilenas para absorber el contingente que egresa de la enseñanza media; con el inicio de la construcción, no sólo de canchas deportivas para la juventud, sino también de grandes centros de cultura y recreación, de albergues juveniles, de centros de turismo juvenil, así como también del plan concreto de construcción de centenares de nuevos establecimientos educacionales que a corto plazo podrán servir a toda la juventud chilena.

Todas estas y otras iniciaetivas, parten del principio de respetar la autonomía y riqueza del movimiento juvenil chileno, pero a su vez de recoger y canalizar sus aspiraciones más sentidas.

Se puede decir con satisfacción y legítimo orgullo que la respuesta del movimiento juvenil chileno frente a la política que el Gobierno de la Unidad Popular ha impulsado, se ha concretado en una acción responsable y fecunda. Prueba de ello es que por primera vez en la historia de Chile los trabajos voluntarios de verano contaron con la presencia activa y responsable de más de cincuenta y cuatro mil jóvenes, que a lo largo y ancho de Chile dejaron como huella profunda no sólo centenares de obras materiales sino, lo que es más importante, una estela de valores morales como el sacrificio, la abnegación y la generosidad. Esto se proyecta hoy con el compromiso de la juventud de incorporarse plenamente a las tareas por elevar la producción en nuestro país, por construir, a través del trabajo voluntario, camino, escuelas, puentes, plazas de juegos infantiles, obras artísticas, etc. Además hoy se ve cómo comienzan los jóvenes a recorrer el país alfabetizando, participando en las tareas de la Operación Invierno comprometiéndose a elevar el rendimiento en sus estudios, a trabajar más y mejor, en una palabra, por este camino del sacrificio y la responsabilidad en las tareas más duras, gestando el hombre nuevo para la nueva sociedad. 


\section{I.- LOS OBJETIVOS DE LA POLITICA SOCIAL.}

La política social del Gobierno Popular ha sido concebida en estrecha vinculación con la acción económica. El remedio de las grandes desigualdades entre los chilenos, en sus manifestaciones sociales, está en función de las transformaciones profundas y aceleradas que tengan lugar en el área económica.

El planteamiento general de la política social se sitúa en dos niveles complementarios aunque distintos. Un primer nivel está constituído por las medidas de emergencia o a corto plazo, para aliviar necesidades imperiosas. El segundo, por el comienzo de innovaciones cuyo desarrollo futuro permite atender mejor no sólo a las insuficiencias presentes sino sobre todo, a las de los años inmediatos.

Se ha prestado atención preferente a los problemas de salud. Durante los meses de verano, por ejemplo, se llevó a cabo una intensa y amplia campaña contra las diarreas infantiles, una de las principales causas de mortalidad infantil, con éxitos muy positivos. Se ha organizado una campaña nacional para asegurar a los niños la disponibilidad de nutrición láctea. $\mathrm{Y}$ se han adoptado medidas de asistencia sanitaria de emergencia, en un esfuerzo para atender el miserable estado en que se encuentran millones de chilenos sobre el particular.

En el campo educativo, se aplicó un plan a corto plazo que duró hasta el mes de Marzo, con el objetivo de hacer frente a imperiosas carencias en el número de aulas y de puestos disponibles. Se racionalizó el procedimiento de matrícula y se incrementó considerablemente el programa de becas y auxilio esciolar.

Paralelamente se ha venido programando un plan educativo a mediano plazo que contribuya a democratizar la educación, en coincidencia con las medidas de fondo que se están aplicando en otros sectores y que ponga la educación al servicio de las necesidades concretas del país, en orden técnico-científico y material. Un $14 \%$ de analfabetismo es desmesuradamente alto para nuestro país.

En el terreno laboral, la colaboración entre la Central Unica de Trabajadores y el Gobierno se ha traducido en amplios acuerdos generales y en acciones concertadas, en cuatro dimensiones principales. En primer lugar, la de satisfacción de reivindicaciones salariales y coyunturales de los trabajadores, lo que ha significado reducir el número de huelguistas en un $70 \%$, en comparación con el último período Noviembre - Febrero de la Administración anterior. En segundo lugar, se han tomado medidas para reconocer la personalidad jurídica a más de 150 nuevos sindicatos y se ha enviado al Congreso un proyecto de ley dotando de personalidad jurídica a la propia Central Unica de Trabajadores. En tercer lugar, se ha enfrentado la lacra de la cesantía, herencia del estancamiento económico del país en los últimos años y agudizada por la campaña psicológica contra el Gobierno Popular. En cuarto lugar, fue elaborado el proyecto de base para organizar la participación directa de los trabajadores en la dirección de las empresas del sector público y mixto. 
En el nivel de realizaciones de nivel más profundo, se ha organizado la Editorial del Estado, instrumento fundamental para el fomento de la política educativa y cultural. Se persigue que la educación general básica abarque al $95 \%$ de todos los grupos de edad, su ampliación de 8 a 9 años y su complementación, para los escolares que no se incorporen a la enseñanza media o superior, de cursos especiales de aprendizaje y capacitación.

En el campo de la salud, el Servicio Nacional de Salud está siendo sometido a reestructuración, a fin de adecuarlo mejor a las necesidades de la planificación.

Se han tomado las primeras medidas que permitan reemplazar el vigente sistema de seguridad social por un Estatuto Unico de Seguridad Social. Y se ha avanzado considerablemente en el camino de establecer el Fondo Nacional de Asignación Familiar, concebido en tal forma que en dos o tres años puedan nivelarse totalmente los montos de las asignaciones. 


\section{II. - EDUCACION}

\section{A.- LA POLITICA EDUCACIONAL}

\section{1.- Planeamiento educativo.}

La realidad educacional y cultural del país permite afirmar que las posibilidades de usar los servicios educacionales y culturales están limitadas por las acentuadas diferencias en la situación socio-económica de las distintas clases sociales. Es así como mientras un grupo reducido, perteneciente a los estratos altos, alcanza un desarrollo biológico $\mathrm{e}$ intelectual en condiciones materiales y culturales privilegiadas, la mayoría de los niños y jóvenes sufren todavía carencias de todo tipo, que repercuten negativamente sobre sus posibilidades reales de ingresar y progresar en el sistema educacional.

En estas condiciones una política de educación que se limite solamente a una expansión numérica de los cupos de matrícula de acuerdo a la demanda es engañosa, pues produce una expansión sólo en la base del sistema. Esto teóricamente favorece a todos los niños, pero en la realidad una parte sustancial de ellos permanece en las escuelas sólo hasta el momento en que las condiciones económicas de sus familias se lo permiten. Más aún, los mismos rendimientos escolares muestran claras diferencias de aprovechamiento entre niños y jóvenes de distintas clases sociales.

La existencia de tipos de enseñanza muy diferenciados e incomunicados, tales como la fiscal y la privada, la científico-humanística y la técnico-profesional, colaboran a crear una orientación de la matrícula altamente estratificada, lo que repercute posteriormente en la vida social y en la del trabajo acentuando los valores característicos de las sub-culturas de clases y las actitudes que menosprecian el trabajo manual.

La Unidad Popular concibe la acción educacional y cultural del Gobierno como un proceso integral de atención a los problemas de la niñez y la juventud, $\mathrm{y}$ a la necesidad de consolidar los valores propios de una sociedad justa y libre, donde se forme y despliegue el hombre nuevo. Para ello se propone elevar los niveles de vida de la población, resolver las necesidades básicas de los estudiantes, promover en ellos una amplia solidaridad social y motivarlos con las grandes metas propias de la construcción de la nueva sociedad.

Consecuente con estos planteamientos la acción del Gobierno de la Unidad Popular, se orientará al cumplimiento de los siguientes obje-
tivos generales:

A. Democratizar el sistema educacional posibilitando la incorporación y la permanencia en todos sus niveles, de los niños y jóvenes sin exclusión por causas socio-económicas, y apertura del sistema a los adultos y trabajadores, como consecuencia de una concepción del proceso educativo como una actividad permanente. 
B. Hacer de la educación un factor que coadyuve decisivamente al proceso de transformaciones estructurales que viva el país, por lo cual ha de estar ligada estrechamente a su realidad social, económica, ocupacional, tecnológica y política.

C. Fomentar los valores que promuevan una amplia solidaridad social y favorezcan la identificación con el proyecto histórico de la nueva sociedad.

Para cumplir los objetivos anteriores es necesario considerar, entre otros, los siguientes aspectos:

a) La organización de un sistema educacional de acceso abierto con matrícula por localización de la demanda efectiva y de la población en edad escolar que no demande educación.

b) Una política de asistencia a los estudiantes orientada a permitir su permanencia y progreso en la escuela hasta completar los ciclos y niveles que se determinen, según sus capacidades intelectuales.

c) Programas educacionales adecuados para compensar las carencias de los menos favorecidos social o intelectualmente (clases remediales, programas de alimentación, etc.).

d) La organización de la gestión educacional de las unidades escolares, en que participen profesores, padres, estudiantes, trabajadores y representantes de las empresas, dentro de líneas centralmente estipuladas.

e) La organización de instituciones paralelas al tronco de formación general común, ligadas estrechamente a las organizaciones de trabajo, que realicen la capacitación y el reentrenamiento profesional no universitario.

f) Una educación con contenidos básicos y actuales que provean al educando de capacidad de adaptación y convertibilidad para variar funciones sociales, con un curriculum que considere materias y actividades experimentales, trabajo práctico, conocimiento y análisis de la realidad nacional.

g) Una organización de la vida escolar que permita al joven participar activamente en su propia formación, ejercitando el espíritu de iniciativa, la responsabilidad, la solidaridad y el amor al trabajo y al esfuerzo.

El estudio de la política educacional conducente a cumplir los objetivos generales y específicos señalados se organizó por etapas:

i) Fue necesario volcar todos los esfuerzos en la elaboración de un plan educacional de corto plazo, tendiente a conocer la situación educacional exacta en que se recibió el país y adoptar las medidas convenientes para ofrecer en Marzo de 1971 las más amplias y mejores posibilidades educacionales, dentro de los lineamientos de la Unidad Popular.

ii) A partir del primer semestre de 1971 se inició la elaboración de un plan educacional a mediano plazo que significa analizar la estructura existente y proponer las realizaciones educacionales del primer Gobierno Popular. 
Es así como en el presente año se da comienzo a una nueva visualización en la solución integral del problema educacional chileno: consiste en la incorporación masiva de todos los sectores vinculados al proceso educativo - trabajadores de la educación, estudiantes, padres y apoderados y demás sectores de la comunidad nacional- al análisis, estudio y discusión de la realidad educacional chilena.

El trabajo de esta primera realidad educacional pretende ser una evaluación y una discusión en torno a su desarrollo, su futuro y sus problemas. Sobre la base de las opiniones que se reciban, se formulará el esquema del plan educacional a mediano plazo.

En consecuencia, la Oficina de Planeamiento de la Educación tendrá la responsabilidad de preparar, bajo la autoridad del Gobierno el Plan de Desarrollo de la Educación a aplicar entre 1972 y 1976. Sin perjuicio de que, desde ya, se anticipen los estudios, técnicos indispensables para la elaboración de este instrumento.

Por lo tanto, habrá un Plan Nacional de Desarrollo Educativo que comprenderá planes regionales y locales, debidamente consultados y discutidos con la comunidad educacional y vigilados y evaluados democráticamente por éste.

\section{2.- PRESUPUESTO.}

Los recursos financieros empleados en 1970 para el funcionamiento de los diversos servicios y establecimientos educacionales, dependientes del Ministerio de Educación, fueron los siguientes y provienen de las fuentes financieras que se señalan:

$\mathrm{E}^{\circ}$ 3.643.294.414, consultados en el presupuesto corriente en moneda nacional, y E $\mathrm{E}^{\circ} 239.374 .000$, consultados en el Presupuesto de Capital, cantidades que totalizan la suma de $\mathrm{E}^{0} 3.882 .668 .414$. En relación con el Presupuesto de 1969, esta cifra determina un aumento neto de $\mathrm{E}^{\mathrm{o}}$ 1.519.012.414.

En el presente año, el actual Gobierno ha asignado al gasto educacional la suma de $\mathrm{E}^{\mathrm{O}} 4.488 .050 .000$, cantidad que involucra, en relación con el año 1970, un incremento real de $14 \%$, sin incluir el alza general de $34,9 \%$, correspondiente a la variación experimentada por el mayor costo de vida.

El presupuesto universitario aumentó $36,8 \%$ en valores reales.

La suma asignada en el presente año de 1971 a la educación nacional corresponde al 16\% del Presupuesto General de la Nación.

\section{PROCESO DE MATRICULA.}

La educación es un servicio social y su organización debe movilizarse para ofrecer el máximo de posibilidades reales de atención para incorporar al sistema educativo a toda la Población en edad escolar.

Para cumplir con este principio se creó una Comisión Racionalizadora de Matrículas que ha llevado a la práctica las siguientes ideas: 
a) Matrícula automática, que consiste en matricular en diciembre a los estudiantes que continuarán sus estudios en el mismo establecimiento. ciales.

b) Reducir los trámites rutinarios de matrícula a los más esen-

c) Gratuidad de la educación en el nivel básico y congelación del valor de la matrícula en el nivel medio.

d) Incorporación del profesorado organizado a través del Sindicato Unico de Trabajadores de la Educación a este proceso de matrícula. Representantes de esta organización actuaron de Coordinadores Provinciales, Departamentales resolviendo regional o localmente los problemas de atención y demanda de matrículas.

e) Incorporación de un proceso mecanizado para el ingreso al primer año medio en las provincias de Santiago y de Valparaíso, que distribuya a los alumnos según sus calificaciones, domicilios y preferencias.

\section{4.- EXPANSION DE LAS MATRICULAS.}

La educación regular de niños atenderá, aproximadamente a 2.570.700 niños durante el año 1971, lo que determina un crecimiento de $6,2 \%$ en relación a la matrícula estimada para el año 1970. La atención de estos alumnos significa escolarizar el $72,5 \%$ de la población de 5 a 19 años.

En materia de educación básica en 1971 se atenderá alrededor de 2.135.100 niños que significa un aumento de 4,7\% en relación a la matrícula en 1970. En números absolutos la matrícula aumentaría en 97.527 alumnos. El incorporar los 2.135.100 niños significa escolarizar alrededor del $95 \%$ de la población de 6 a 14 años, porcentaje superior al observado en 1970. El incremento de la matrícula básica fiscal sería de 73.145 alumnos lo que determina la necesidad de crear aproximadamente 2.000 cursos, para lo que se aprovechará la desocupación actual de profesores normalistas.

El nivel medio atenderá en 1971, aproximadamente a 360.800 alumnos distribuidos en 223.100 en científico-humanística y 137.700 en técnico-profesional. El sector fiscal absorberá a 175.126 y 106.428 alumnos respectivamente, que significan un crecimiento de $20,1 \%$ en la primera modalidad y $37,1 \%$ en la segunda. Al sector privado, en consecuencia, le corresponderá atender al 22,9\% de las matrículas de la enseñanza media. Al atender a este número de alumnos se alcanzará una escolarización de $34,7 \%$ de la población de 15 a 19 años, porcentaje superior al observado en 1970. Alcanzar esta matrícula significa la absorción de $\mathbf{5 8 . 4 0 0}$ personas, esfuerzo bastante considerable si se tiene en cuenta que, históricamente, se ha incorporado como máximo a 40.000 alumnos.

La modalidad de enseñanza científico-humanista tendrá el $62 \%$ de la matrícula total de la enseñanza media. Si bien es un porcentaje bastante elevado, considerando que el objetivo de esta enseñanza es la formación general y continuación de estudios superiores, es inferior al 
observado en 1970 como resultante de la reorientación hacia la modalidad técnico-profesional que se quiere lograr en el mediano plazo, que en esta primera etapa quedará condicionada a las disponibilidades materiales existentes. El aumento de matrícula será de 30.000 alumnos, en el sector fiscal. En la atención de los nuevos alumnos de esta modalidad en el sector fiscal se requerirá un incremento de 747 cursos con 26.900 horas de clases, lo que representa un 20\% de aumento con respecto de 1970. Para este efecto se aprovecharán algunas horas desocupadas de los profesores existentes en la actualidad y nuevas contrataciones.

La educación técnico-profesional absorberá el $38,1 \%$ de la matrícula de la enseñanza media. Durante 1971 se pondrá especial énfasis en el desarrollo de la educación industrial y agrícola, aumentando la matrícula de la primera en un 52\% y un 55\% la matrícula de la segunda. Al sector fiscal le corresponderá absorber a 13.700 nuevos alumnos en industrial a 6.550 en comercial, a 1.110 agrícola y 4.000 en enseñanza técnica. Para la atención de alumnos, el sector fiscal requiere de la creación de 615 cursos y 31.000 horas de clases. Para la absorción de esta necesidad se actuará igual que en la modalidad anterior.

En el nivel universitario el ingreso al primer año aumenta en un 87\%. La matrícula total aumenta en un 28\%. Del año 1969 a 1970 este aumento fue sólo del $8 \%$.

\section{5.- PROGRAMA DE CONSTRUCCIONES ESCOLARES}

A requerimiento del Gobierno y con el objeto de posibilitar el programa extraordinario de expansión de matrícula impulsado por la actual administración, la Sociedad Constructora de Establecimientos Educacionales elaboró y ha dado término a un amplio Plan de Urgencia de edificaciones escolares. Este Plan se inició en Febrero y en 75 días de plazo logró construir 1.844 aulas, con $137.829 \mathrm{~m}^{2}$. que tienen una capacidad para $\mathbf{1 6 2 . 8 1 0}$ alumnos en un sistema de doble turno. Las aulas se distribuyeron entre las provincias de Tarapacá y Aysén, con preferencia en las poblaciones obreras de las grandes ciudades.

Por la calidad y cuantía de las obras que comprende el Plan de Urgencia y por el corto margen de tiempo provisto para su desarrollo, constituye una de las realizaciones más valiosas llevadas a cabo en el pais en beneficio de la edificación escolar.

Con el objeto de enfrentar las necesidades educacionales de la población de los "campamentos" de Santiago, en el contexto de la Operación Invierno, se ha recurrido a una solución de emergencia: con la colaboración de la Corporación de Servicios Habitacionales (CORHABIT), la Empresa de Transportes Colectivos del Estado (ETC) y del Ejército, se han habilitado y adoptado como aulas 300 buses dados de baja, para atender provisoriamente la escolaridad básica de 24.000 niños en doble turno.

El programa de construcciones para el año presente comprende un total de $248.991 \mathrm{~m}^{2}$. de edificación, de los cuales 137.829 corresponden al Plan de Urgencia ya cumplido, $9.728 \mathrm{~m}^{2}$. a obras del Plan Normal ya contratadas y $101.364 \mathrm{~m}^{2}$. por contratarse. 
Cabe hacer notar que la ejecución de este programa significará un incremento de $\mathbf{2 1 0 , 4 5 \%}$ en relación con la superficie construída en 1970.

\section{6.- PROGRAMA DE LA JUNTA DE AUXILIO ESCOLAR Y BECAS.}

El programa de Atención de la Junta Nacional de Auxilio Escolar y Becas para el año 1971, es el siguiente: neficios:

En alimentación y material escolar, se otorgarán los siguientes be-

a) Se atenderá durante 150 días, un promedio diario de 600.000 alumnos, con almuerzo. Esto representa un aumento del $53,45 \%$ en relación a 1970 .

b) Durante 180 días, recibirán desayuno, un promedio diario de 1.800 .000 alumnos, lo cual representa un aumento del $44 \%$, respecto de 1970.

c) Se ha mejorado la calidad de la ración en un $54,4 \%$ (de $\mathrm{E}^{\mathrm{0}} 3,88$ diarios a $\mathrm{E}^{\mathrm{0}} 6,00$ ). tuario:

d) Se entregarán los siguientes elementos escolares y de ves-

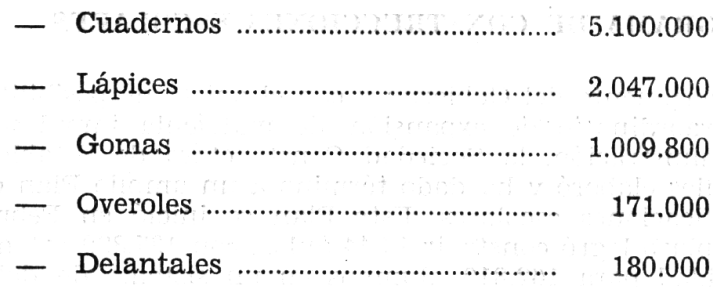

Se encuentra programada la entrega de 500.000 pares de zapatos, lo que significa atender en este rubro el $24 \%$ de los escolares de nivel básico.

e) En materia de becas, se otorgará a los alumnos de $7^{\circ}$ y $8^{\circ}$ año y Enseñanza Media, un total de 60.000 becas, lo que representa un 56,67 de aumento sobre los beneficios otorgados el año 1970.

f) En materia de colonias escolares, el año 1971, se atenderá un mínimo de $\mathbf{8 0 . 0 0 0}$ alumnos en colonias de verano e invierno, para

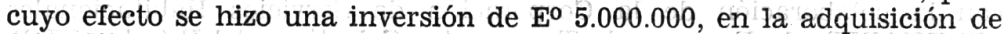
3.500 literas, 7.000 colchones de espuma, 7.000 almohadas y 14.000 frazadas.

\section{7.- PROGRAMA DE EDUCACION DE LOS TRABAJADORES PARA EL CAMBIO.}

Alrededor de 900.000 chilenos mayores de 15 años no han tenido acceso a las más elementales formas de educación (14\% de analfabetismo). 
Es necesario no sólo alfabetizar este contingente de personas, sino que también ofrecerle mayores oportunidades y medios para alcanzar mejores niveles de educación.

Es conveniente, vincular los esfuerzos de alfabetización de la población adulta con los centros de trabajo, los sindicatos, las Fuerzas Armadas y los Centros Habitacionales.

Muchas campañas de alfabetización se han desarrollado en el país y todas, hasta ahora, han tenido pobres resultados.

El Gobierno de la Unidad Popular aborda el programa del analfabetismo como parte del problema cultural del pueblo que a su vez está estrechamente vinculado al desarrollo socio-econónico del país y a su estructura económica.

El Programa de esta Campaña de Educación de los Trabajadores para el cambio tiene como objetivos fundamentales:

- Erradicar el analfabetismo. ducción.

- Contribuir a capacitar al trabajador en nuevas técnicas de pro-

- Promover una participación auténtica de los trabajadores en esta etapa de cambios estructurales.

- Crear las condiciones para que el trabajador tenga acceso real al sistema educativo.

\section{COMISION RACIONALIZADORA DE LOS SERVICIOS ADMINIS- TRATIVOS DE EDUCACION.}

Los servicios administrativos del sistema educativo deben estar organizados para cumplir los fines sociales y la política educacional que postula el Estado.

Se ha constatado que uno de los aspectos más rígidos y disfuncionales es la administración de la Educación, esto es todo el mecanismo necesario para desarrollar el proceso educativo. Entre otras muchas cuestiones que se relacionarán con este problema se puede señalar que es urgente buscar soluciones a: nombramiento de personal, asunción de cargos, beneficios del personal, supervisión de la enseñanza, presupuesto, certificaciones de estudios, etc.

Consciente de este hecho y con el propósito de conocer la realidad de todo el proceso de la administración del servicio educacional, el Ministerio ha creado la COMISION RACIONALIZADORA DE ADMINISTRACION integrada por funcionarios de la Contraloría General de la República y técnicos del propio Ministerio.

Esta comisión, dentro de las disposiciones legales vigentes, deberá sugerir medidas inmediatas de aplicación de normas administrativas que sean factibles para agilizar los trámites de rutina. ber:

La Comisión, por otra parte deberá cumplir otros cometidos, a sa- 
La primera preocupación de esta Comisión fue incluir en la última Ley de Presupuesto la disposición que dio estabilidad en sus cargos a los profesores de enseñanza básica y media cuyos nombramientos tenían el carácter de interinos.

Actualmente la Comisión se encuentra abocada a la redacción de un Proyecto de Ley Orgánica del Ministerio de Educación Pública, que constituye una necesidad urgente.

\section{9.- EDITORIAL DEL ESTADo.}

Una de las primeras medidas importantes adoptadas en materia educacional, fue constituir una comisión de alto nivel que estudiara la creación de un organismo denominado Editorial del Estado.

Esta comisión se constituyó con representantes de las Universidades, de la Sociedad de Escritores de Chile, de la Sociedad de Actores Teatrales de Chile y otras entidades vinculadas con la actividad gráfica y editorial.

Al terminar su cometido, esta comisión evacuó un completo informe que será elemento importante de la política que, en esta materia, propiciará el Supremo Gobierno.

Los propósitos que inspiran la creación de una Editorial del Estado están contenidos dentro de la gran política que el Gobierno Popular postula en materia cultural y educacional.

Esta Editorial del Estado debe preocuparse de la edición de textos escolares que le encomiende el Ministerio de Educación Pública, con miras por una parte, a producir a bajo costo, y por otra, a entregarlos a este organismo en condiciones tales que le permita cumplir la tarea que se ha impuesto de proporcionarlos gratuitamente a los estudiantes de la Enseñanza Básica y, en lo posible, de la Enseñanza Media.

La Editorial debe, además, atender a múltiples otras necesidades culturales, ligadas todas a la urgencia de ofrecer a la población obras que ayuden al desarrollo científico y tecnológico, al fomento de la literatura nacional $\mathbf{y}$, sobre todo, que sirvan para profundizar el estudio de Chile, de su realidad histórica, geográfica, económica, etc.

A este respecto, el antoproyecto de ley fue entregado al Presidente de la República y pronto se enviará para la consideración del Parlamento.

\section{LABor Del Centro de Perfeccionamiento.}

El Centro dio término a la elaboración de los proyectos de Programas de Estudio para el $4^{\circ}$ año de Educación Media Científico Humanística, los cuales fueron propuestos a la Superintendencia de Educación Pública. En cuanto a los Programas de Estudio para el $4^{\circ}$ año de la Educación Técnico Profesional, el Centro tuvo a su cargo la supervisión de su elaboración. 
Perfeccionamiento del personal. En Enero de este año se celebró, un seminario para el personal docente directivo, con asistencia de más de 500 funcionarios, y en Febrero se realizó una seminario para profesores del Plan Diferenciado con participación de más de 700 maestros.

Iniciativas adoptadas por la Superintendencia de Educación en relación con actividades del Centro Nacional de Perfeccionamiento, Investigación y Experimentación.

- Se encuentra en un proceso de elevar cada vez más el nivel cualitativo de los seminarios y jornadas de perfeccionamiento.

- Ha extendido al máximo las oportunidades de perfeccionamiento a todo el Magisterio Nacional.

-Desarrollo de investigaciones educacionales tendientes a incorporar nuevas técnicas de trabajo docente.

-Administración y realización de Seminarios y Cursos en coordinación con el SUTE.

-Se aceleró la obtención de la asignación de perfeccionamiento, establecida por la legislación vigente.

- Se ha estudiado la ampliación y profundización de nuevos sistemas y métodos de perfeccionamiento que permitan descentralizarlo, ofreciendo oportunidades a todos los profesores de todos los niveles del sistema en su propio lugar de trabajo.

\section{PARTICIPACION DEL MINISTERIO DE EDUCACION PUBLI- CA EN EL "PROGRAMA DE DESARROLLO ECONOMICO SO- CIAL PARA LAS PROVINCIAS DE MALleco, CAUTIN $Y$ VALDIVIA".}

\section{OBJETIVOS:}

Participar en la elaboración y realización del plan global de desarrollo para la región.

Procurar que dicha región pueda servir de zona de experimentación para la puesta en marcha del plan de reforma integral de la educación.

\section{ETAPAS DEL PRograma CoRrespondente al SECTOR EDU- CACION.}

1. Medidas de acción inmediata.

2. Estudio prospectivo y de diagnóstico.

3. Elaboración de un plan de desarrollo e integración educativa concordante con el plan global que se proponga para dicha zona y que, a la vez, sirva al planeamiento integral de la educación. 


\section{Medidas de acción inmediata.}

Dadas las características de los problemas socio-económicos de la región ha sido imprescindible adoptar medidas de acción cuyos efectos puedan producir un impacto de cambio en el status actual. En este sentido el Ministerio de Educación ha puesto en marcha el siguiente plan de acción.

1.1. Se ha intensificado la campaña de matrículas procurando incorporar toda la población en edad escolar al sistema educativo. La campaña se acentuó en el área rural.

ANTECEDENTES: Aproximadamente el $60 \%$ de la población vive en el área rural.

Existe un bajo nivel educativo de la población, de suerte que el perfil cultural presenta un alto volumen de población inescolarizada o con escasos años de escolaridad.

MEDIOS O RECURSOS: Coordinadores zonales y provinciales de la campaña de extensión de matrículas.

1.2. Activar la campaña de alfabetización.

ANTECEDENTES: El porcentaje de analfabetismo de la población mayor de 15 años es de aproximadamente un $25 \%$. Porcentaje que como se comprenderá, es muy superior en el área rural.

MEDIOS O RECURSOS: Campaña de educación de los trabajadores para el cambio.

1.3. Se incrementó el número de becas y préstamos concedidos por la Junta de Auxilio Escolar y Becas y se coordinarían con las que ofrezcan otros organismos. Deberá orientarse este servicio asistencial, preferentemente, a la población escolar rural.

1.4. Se han activado las construcciones escolares y se han ampliado varios locales, con el objeto de posibilitar la total incorporación de la población en edad escolar y completar los grados de las escuelas incompletas.

ANTECEDENTES: Un alto porcentaje de escuelas de esta zona son incompletas y no ofrecen posibilidades de continuidad educativa a la población rural.

MEDIOS O RECURSOS: Oficina Técnica para el Plan Extraordinario de Edificación Escolar.

1.6. Están organizados y se seguirán organizando en colaboración con INACAP cursos de formación profesional intensiva (industrial, agropecuaria y pesquera).

ANTECEDENTES: Estudios de INACAP indican que el 60\% de la fuerza de trabajo del país tiene menos de 6 años de escolaridad y que en esta zona, dado el alto porcentaje de analfabetismo, no puede ser mayor de 3 años.

La escasa escolaridad produce una baja calificación profesional de la población activa $y$, como consecuencia, una incipiente productividad. 
Esta constelación de hechos configuran una incipiente movilidad social y una insignificante promoción cultural y económica.

MEDIOS O RECURSOS: INACAP, Departamento de Educación Industrial, Departamento de Educación Agrícola, Departamento de Educación Técnica Femenina.

\section{2.- COMISION CONTRA EL USO DE DROGAS EN LA JUVENTUD.}

En uno de los primeros Consejos de Ministros se abordó el candente problema de la juventud y el consumo de drogas.

Los Ministros de Educación y Salud fueron designados para hacer un estudio de la realidad del problema y proponer medidas concretas tendientes a su solución.

Con tal propósito los Ministros nombraron una Comisión integrada por especialistas: médicos, sicólogos, educadores y asistentes sociales de distintos organismos e instituciones quienes elaborarán un informe que servirá de base para poner en marcha una acción coordinada del Gobierno y la comunidad para hacer frente a un problema que puede tener consecuencias imprevisibles para la sociedad chilena.

En consideración a que de un tiempo a esta parte se han agravado los hechos que dieron origen al funcionamiento de esta Comisión, se han acelerado y volcado la totalidad de los esfuerzos tendientes a concretar medidas que aborden de inmediato el problema señalado.

\section{3.- EDUCACION SUPERIOR.}

Las vacantes para los primeros años de las Universidades se incrementaron en un $87 \%$ en relación a las disponibles en 1970 . Si a ellos se agregan las 6.500 plazas que ofrecerán a los egresados de enseñanza media INACAP, el Instituto Laboral, el Instituto Politécnico, el INAPROCC y otros organismos, se llega a un aumento del $118 \%$ en las oportunidades de educación para los egresados de enseñanza media.

Por su parte, la matrícula total de las universidades alcanzará a aproximadamente 97.000 alumnos y el total de la enseñanza superior (incluyendo esta promoción extraordinaria de INACAP, y otros Institutos y la enseñanza normal), alcanzará a 107.000 alumnos.

Mención especial merecen las iniciativas destinadas a democratizar el ingreso a la Universidad, entre ellos la incorporación de trabajadores a la educación superior.

Cuando se analiza el crecimiento de las vacantes por áreas, se observa que el área de la Ingeniería y Tecnología, más directamente vinculada con el desarrollo nacional, es la que ha crecido más, llegando al $171 \%$.

\section{PAPEL DE LA EDUCACION PRIVADA.}

La educación particular tiene su lugar como parte integrante del sistema educacional. La enseñanza gratuita mantendrá y perfeccionará sus actuales derechos, a condición de que eleve su calidad, remunere adecuada y regularmente a sus personales, mejore sus locales 
y disminuya la carga de alumnos por curso. La enseñanza pagada deberá integrarse efectivamente al sistema nacional de educación, de manera que sus cobros no den motivo a lucro - porque la educación no puede ser considerada como negocio- y desaparezca todo vestigio de segregación cultural o social con sus alumnos. En cuanto a los institutos o academias que ofrecen cursos cortos, con certificados o títulos no reconocidos, o sistemas de recuperación de estudios o de preparación para pruebas nacionales, el Estado vigilará que no sigan constituyendo una defraudación a la confianza pública. Al mismo tiempo, el Estado ofrecerá tanto a través del sistema regular como del sistema paralelo de educación de la comunidad, oportunidades suficientes para regularizar o continuar estudios o iniciar otros que califiquen o recalifiquen, con el debido respaldo técnico y validez legal.

\section{B.- POlitica educacional a largo plazo}

1. La educación general básica debe cubrir alrededor del $95 \%$ de los correspondientes grupos de edad en los próximos cinco años. Para alcanzar esta meta es necesario incorporar a los primeros años a toda la población infantil en edad escolar y hacer un gran esfuerzo para retener a los niños en la escuela, es decir, evitar la deserción.

Para incorporar a toda la población infantil será necesario habilitar escuelas-internados en ciudades cercanas a zonas donde existe una gran dispersión poblacional. (Estos internados pueden ser, en algunas partes, residencias especiales sin incluir escuelas).

Para evitar la deserción hay que implementar un buen programa de becas, alimentación, salud, vestuario escolar y actuar en las causales pedagógicas que la provocan (por ej.: las repeticiones de curso, ${ }^{1}$ uniformidad de los programas y otras).

2. La educación general básica aumentará de los ocho años actuales a nueve años, a fin de fortalecer la formación general de toda la población. Todas las escuelas de educación básica del país completarán los nueve años, siendo ésta una de las metas que se alcanzará en la primera etapa del gobierno. Comenzará este ciclo a los seis años de edad, como norma general.

3. Los jóvenes que egresen de la educación básica y que no se incorporen a la educación media, entrarán a un sistema de aprendizaje en el trabajo, recibiendo un entrenamiento técnico teórico breve y uno práctico en el mismo tipo de organización en que tendrán ocupación. Habrá, pues, que organizar este aprendizaje que entregará a las organizaciones de trabajo responsabilidades educacionales y establecer mecanismos que relacionen las escuelas con las empresas, a lo cual se aludirá más adelante. Se crearán las condiciones para que estos jóvenes tengan la oportunidad de volver al sistema educacional, diurno o nocturno.

4. La educación media tendrá tres años de duración. Se terminará con la separación entre la educación científico-humanista y técnico-profesional, la que enseña un oficio en talleres ad-hoc.

1. Las repeticiones de curso, que son excesivamente numerosas en nuestro país, constituyen una de las principales causales de deserción de los alumnos que provienen de los sectores populares. 
La educación media se realizará en escuelas integradas o completas, en establecimientos que atiendan jóvenes de todos los niveles de capacidad de una localidad o región geográfica determinada.

Con ello se procura que la enseñanza profesional y la general tengan el mismo nivel y se estimulan las transferencias entre ambas, de acuerdo a los intereses, capacidades y necesidades de los alumnos. La escuela media integrada permitirá superar la valoración negativa del trabajo manual o técnico, ya que todos los estudiantes adquirirán principios básicos humanísticos, científicos y tecnológicos.

La escuela media tendrá un curriculum flexible, la enseñanza se hará a distintos niveles para alumnos de los mismos cursos con profesores de tiempo completo en su mayor parte.

La educación técnica que se realice en la escuela media integrada será de nuevo tipo. No se pretenderá enseñar un oficio a cada alumno en talleres especiales. (Baste decir que hoy es posible identificar alrededor de 800 ocupaciones de nivel medio y la actual educación técnicaprofesional alcanza a preparar alrededor de 50 ocupaciones). La nueva educación técnica que se realice en la escuela media será teórica, versará acerca de los principios de las técnicas que correspondan a un área de interés general seleccionada por el alumno. Para este tipo de educación no se necesita instrumental completo y caro, aunque sí profesores bien calificados.

El oficio de nivel medio, es decir, la educación técnica práctica, se enseñará en la organización de trabajo. Los egresados deben ser personas con capacidad para ser entrenables: habrán aprendido a aprender.

Todos los alumnos que egresen de la enseñanza media integrada tendrán la misma certificación de sus estudios, en la cual se incluirán los estudios específicos seguidos.

5. Todos los egresados de la educación media irán a una experiencia de trabajo de uno o dos años, en el área de interés detectada. en la escuela integrada.

En las organizaciones de trabajo los jóvenes serán atendidos por especialistas que les darán un entrenamiento ocupacional, de nivel "mando medio", en contacto íntimo con el empleo, adquiriendo así una "profesión" dentro del área de interés.

El entrenamiento especializado en estrecho contacto con la organización empleadora posibilita una mejor coordinación entre el entrenamiento y las demandas del mercado de trabajo, proceso de enseñanza -aprendizaje más realista, mejores ventajas en la disponibilidad de especialistas, y menor costo de equipos, más posibilidades de motivar profundamente a los jóvenes a través de la experiencia real, lo que repercute en menores pérdidas y deserciones.

Una experiencia de trabajo de este tipo para todos los jóvenes es insustituible en la formación de una solidaridad social amplia, en la comprensión de la función de la clase obrera y una posibilidad de identificación con las grandes metas sociales que se propongan. 
Para una tarea de este tipo habrá que movilizar recursos educacionales, tales como Universidades, escuelas técnicas, INACAP y recursos ingenieriles y empresariales.

6. Algunos de los jóvenes volverán al sistema educacional regular, después de uno o dos años de entrenamiento en el trabajo, incorporándose a la Universidad, donde estudiarán una profesión (entre las que se incluirá la profesión de científico), durante tres o cuatro años. Los problemas de descoordinación, duplicación y otros, característicos de la educación universitaria actual, se evitarán por medio de la organización de un sistema nacional de educación superior.

Con su título que los habilite para el desempeño profesional de nivel superior volverán al trabajo.

Para efectuar estudios de post-grado se exigirá una experiencia de trabajo, posterior a la obtención del título profesional. Estos estudios se realizarán en el seno de las Institutos de Investigación. En este nivel se generarán los científicos, especialistas y profesionales de alta calificación necesarios para la enseñanza universitaria, la investigación científica y tecnológica, y para los puestos de dirección superior en la producción y los servicios.

Los jóvenes de educación básica y media que no terminen el respectivo ciclo de estudios tendrán oportunidad de recibir un entrenamiento ocupacional rápido.

8. Dado que todos los jóvenes que salgan del sistema de educación regular - hayan terminado o no el respectivo ciclo de estudiosrecibirán entrenamiento en el trabajo se necesita construir una organización nacional que atienda a esta función.

Tal organización deberá estar vinculada con el Ministerio de Educación, el Ministerio del Trabajo, con el sistema nacional de educación superior, INACAP, SENDE, sectores sindicales y empresariales. Es muy deseable que ella tenga una cierta autonomía en relación a los Ministerios.

Desde el punto de vista de las prioridades en educación el "programa de educación en el trabajo" tendrá una destacada preferencia.

\section{PROPOSICIONES PARA RESOLVER LOS PROBLEMAS IDENTIFI- CADOS.} colar.

1. Extender, integrar y mejorar los servicios de asistencia al es-

2. Actuar sobre los factores endógenos del sistema educativo, para mejorar su eficiencia interna (edificios, curriculum, equipamiento, preparación del personal docente y de supervisión).

Institucionalizar y promover la obligación del perfeccionamiento y la capacitación de los docentes en vistas a satisfacer los requerimientos culturales y profesionales del personal en servicio, la preparación para desempeñar nuevas funciones y la ejecución de proyectos de mejoramiento cualitativo.

3. Realizar y aplicar los estudios necesarios para asegurar que las modalidades y especialidades de la educación del nivel medio y su- 
perior se ajusten a las necesidades del mercado ocupacional en el orden nacional, regional y local.

4. Integrar en el Sistema Nacional de Planeamiento al organismo sectorial de planeamiento educativo, encargado de diagnosticar, programar y evaluar las actividades del sector.

5. Aplicar a la Administración Escolar las recomendaciones de los organismos de Organización y Métodos y utilizar las técnicas de la programación presupuestaria.

6. Integrar los programas de alfabetización y educación del adulto en los más generales de educación permanente, procurando ofrecer estas oportunidades a toda la población.

7. Racionalizar los servicios administrativos y docentes y estudiar sus costos operativos, así como lograr la óptima utilización de los recursos físicos, humanos, financieros e institucionales disponibles.

8. Celebrar y ejecutar convenios de coordinación de servicios y asistencia técnica con Universidades, Junta Nacional de Jardines Infantiles, Instituto Nacional de Capacitación Profesional, etc.

9. Experimentar nuevas técnicas pedagógicas y formas de organización, supervisión y evaluación de la enseñanza; continuar la ejecución del programa de mejoramiento del curriculum.

10. Incrementar los recursos necesarios para el equipamiento en orden a contribuir a la "tecnificación" de la enseñanza, y mejorar los mecanismos con los que se prestan los servicios de Documentación e Información.

11. Asegurar la igualdad de oportunidades de educación procurando extender los beneficios de la misma a toda la población, especialmente en los años de escolaridad sistemática obligatoria a fin de evitar las diferencias existentes entre los sectores urbano y rural.

\section{OTRAS PROPOSICIONES}

1. Alfabetización: Al particular hay que precaverse acerca de las campañas espectaculares, que no consiguen resultados acordes con el esfuerzo desplegado. El concepto de alfabetización funcional supone la capacidad de los educadores para responder a las necesidades vividas por los adultos en su experiencia cotidiana. El aprendizaje debe ser un proceso activo que enfatice la relación entre las actividades que los analfabetos realizan y las nuevas que les facilitará su alfabetización.

Por lo anterior es conveniente vincular los esfuerzos de alfabetización de la población adulta con los centros de trabajo, los sindicatos, las fuerzas armadas y los centros habitacionales. En este trabajo pueden tener un papel importante los jóvenes egresados de la educación media que se interesan por el área educacional. Es importante aquí, como en otros respectos, desarrollar el talento creativo de especialistas educacionales que creen los materiales y las orientaciones pedagógicas adecuadas.

2. Polos de atracción cultural: Es conveniente estimular o reforzar el desarrollo de polos de atracción cultural, aparte de Santiago y 
Valparaíso. La descentralización de la administración educacional se combinará con este propósito, de modo de crear en estos polos organismos de investigación educacional, de perfeccionamiento del profesorado, de publicaciones docentes, de supervisión, etc. Ellos pueden convertirse en asiento de universidades, internados, etc.

3. Instituto de creación de materiales audio-visuales: Es de extraordinaria urgencia contar con un organismo, formado por personal idóneo, encargado de crear materiales audio-visuales, que pueden usarse masivamente tanto en el sistema regular de educación, como en los medios de comunicación de masas. También es necesario contar con una editorial especializada en la publicación de material pedagógico.

4. Evaluación, orientación y perfeccionamiento: Todo el proceso de vinculación de educación y trabajo hace indispensable aplicar sistemas modernos de evaluación y orientación, tanto a nivel de alumnos como de profesores. Por otro lado, un programa prioritario dentro del sistema debe ser el de perfeccionamiento masivo de profesores y otros profesionales que participan en la enseñanza en la escuela y en los frentes de trabajo.

5. Educación extraescolar: En la vinculación de educación y actividad de trabajo, y en la de las escuelas con empresas, sindicatos, organismos vecinales irá conformándose una modalidad de educación en la sociedad - que algunos denominan con el concepto de "sociedad docente",- que el desarrollo de los medios de comunicación de masas, las necesidades de permanente entrenamiento y reentrenamiento de la población adulta, el rápido desenvolvimiento de la ciencia y la técnica harán que sea cada vez más decisiva en el destino de la nueva sociedad. Para enfrentar esta tarea es imprescindible promover la creatividad en la esfera de la investigación y experimentación pedagógica y cultural en general.

6. Sistema nacional de educación superior: La idea de autonomía universitaria no se contradice con la necesidad de crear un sistema nacional de educación superior. La orientación de dicho sistema debe estar estrechamente vinculada con la política que impulse el Ministerio de educación.

Es necesario estudiar detenidamente las líneas generales de una pólítica universitaria y, en relación con ellas, analizar el actual proyecto de ley que crea este sistema nacional y que pende de la consideración de la Comisión de Educación del Senado.

Algunas de las líneas de política universitaria dicen relación con el acceso al primer año: cupos de matrícula, su orientación por especialidades, por regiones, por Universidades, etc.; investigación científicas; integración regional de las unidades universitarias independientes; sistemas de pre-grado y post-grado; aumento de la eficiencia del sistema tanto en docencia como en investigación y difusión; financiamiento; participación en las tareas de transformación económica $\mathrm{y}$ social; planificación de la educación superior, etc.

7. La política de remuneraciones del profesorado y la organización de su carrera docente deben concertarse con los gremios del magisterio. Es de todo punto de vista conveniente aprovechar esas dos poderosas herramientas para estimular el trabajo docente de mayor calidad. 


\section{III.- SALUD PUBLICA}

\section{1.- INTRODUCCION.}

La política económica y social que se ha propuesto realizar el Gobierno, considera que la salud es un deber del Estado y un derecho de todos los habitantes del país. Por lo tanto el pueblo, según sus necesidades, debe tener pleno acceso a los servicios que proporcionan salud.

Continuando la política que inspiró la Ley 10.383, que creó el Servicio Nacional de Salud, en la gestación de la cual correspondió un papel importante a los parlamentarios de izquierda y en particular al actual Presidente de la República, es un propósito irrenunciable del Gobierno Popular ir a la estructuración del Servicio Unico de Salud que dé, a toda la población, la posibilidad de hacer una realidad este derecho en tal forma que la atención médica que se reciba sea eficiente, oportuna, igualitaria, continua, suficiente y gratuita.

El Gobierno tiene conciencia que para llegar a la constitución de un Servicio Unico de Salud se hace indispensable, previamente, mejorar substancialmente la cantidad de prestaciones que da el actual Servicio Nacional de Salud y los Servicios Estatales y sobre todo, elevar el grado de humanización y su calidad, mediante un proceso de desburocratización, descentralización y democratización.

Democratización de los servicios, descentralización y participación popular deberán ser armonizados convenientemente para que constituyan la piedra angular de los nuevos servicios. La descentralización permitirá a las autoridades locales responder del mantenimiento del nivel de salud de la población a su cargo, programando sus acciones de acuerdo con la demanda y la disponibilidad real de medios, así como de suficiente independencia ejecutiva para el cumplimiento de los presupuestos-programa. La democratización permitirá asumir la responsabilidad que cada cual tiene en el cumplimiento de las metas del programa y la participación popular garantizará la utilización adecuada de los recursos en la satisfacción de las reales necesidades de salud de la población.

Para obtener estas condiciones los trabajadores de la salud, sin distingos, deberán unir fervor, mística y sacrificio al desempeño de su obligación. Sólo así se podrá cumplir la enorme responsabilidad que significa dar atención médico-asistencial de alta calidad. Entendemos que todos los procesos revolucionarios de cambios profundos como el que estamos emprendiendo, requieren fundamentalmente que la revolución se inicie en el espíritu mismo de las personas que participan en ella. La revolución debe empezar en uno mismo. 
Dentro de este proceso tendrá un papel importante el pueblo formado por los trabajadores organizados, las Juntas de Vecinos, los Centros de Madres, así como por otras instituciones. A ellos corresponderá velar porque el trabajo que se desarrolle en su beneficio, cumpla con los objetivos para los cuales fueron creados y dé satisfacción a sus legítimas aspiraciones de un trato amable y humano.

La salud la concebimos como un proceso dialéctico, biológico y social, producto de la interacción entre el individuo y el medio ambiente, influído por las relaciones de producción en una sociedad dada que se expresa en niveles de bienestar y de eficiencia física, mental y social. Por lo tanto, la salud es primero que nada, un problema de estructura económica y social, de niveles de vida y cultura. Sólo el Gobierno Popular que llevará a la construcción de una sociedad socialista, podrá solucionarlo integralmente. Sin esta base indispensable, los esfuerzos de salud serán infructuosos.

La economía, organizada y movida con fines de lucro, se manifiesta también en el campo de la salud. La comercialización de las prestaciones médicas corrompen el sentido ético y moral inherente a nuestro trabajo. La medicina se realiza en un sentido esencialmente reparativo, mientras la prevención y la rehabilitación sólo aparecen en el papel. Esta situación discriminativa en Salud y su sentido de clase aparece claramente definido en la distribución que de ella se hace. El 60\% de estos recursos se gastan en el sector privado que no alcanza a un $25 \%$ de la población. El $40 \%$ restante es utilizado por el sector público que debe atender a más del $75 \%$ de los chilenos.

La creación del Servicio Unico de Salud deberá resolver estas contradicciones y entregar al pueblo una atención médica con sentido social y democrático.

Además de la absorción de la demanda creada por el aumento vegetativo de la población, el Gobierno deberá hacer llegar las atenciones de salud a los sectores de la población hoy día al margen de las mismas, aumentando principalmente la cobertura de los sectores rurales y de las comunidades suburbanas. Esta política se cumplirá dándole prioridad a la atención externa ambulatoria, para lo cual se extenderá la red de consultorios periféricos y se les situará en el seno mismo de las Comunidades más necesitadas. En ellos se proporcionará una atención médica integral, que abordará los problemas desde su prevención y se atenderá a la familia en su conjunto asignándosele importancia, no sólo a los factores biológicos, sino también a los factores sociales, económicos y políticos que los condicionan. De este modo, se incrementará la cobertura de la población, lo cual exigirá, probablemente un aumento proporcional del número de camas de hospital y una mejor utilización de este recurso, lo que también está siendo programado.

El Gobierno ha señalado, insistentemente, la importancia que debe dársele a los programas de atención materna e infantil. No obstante los progresos observados en los últimos años, se estima que una de las causas primordiales del problema radica en las deficiencias de la alimentación-nutrición de vastos sectores de la población y en especial de las madres, de los lactantes, preescolares y escolares. No debe olvidarse la mal nutrición de los niños de corta edad, asociada al sindrome policarencial 
de la miseria, que los afecta en lo social, en lo cultural y en lo afectivo y que los puede llevar no sólo a un desarrollo pondoestatural inadecuado sino que a un estado mental deficitario irreversible.

En estos programas de expansión se estructura también la atención odontológica que requiere una urgente modificación de su enfoque global y particular. En la actualidad, la atención dental es preferentemente mutiladora. Se requiere de un esfuerzo coordinado de las Universidades, de los Servicios y de los profesionales con el objeto de crear el equipo de atención odontológica que necesita la población y que, en opinión del Ministerio de Salud Pública, es la única forma racional de abordar el problema de la salud oral.

El país deberá hacer esfuerzos de consideración para el mejoramiento de la higiene y saneamiento del ambiente. Si bien los núcleos urbanos disponen, en general, de agua potable, cuya calidad sin embargo debe mejorarse, las comunidades suburbanas y rurales acusan un grave déficit que pesa seriamente sobre la salud y es causa importante de nuestra elevada mortalidad infantil. En cuanto a la disposición de aguas servidas la situación es francamente desfavorable, aún en las ciudades, ninguna de las cuales cuenta con plantas de tratamiento, razón por la cual la contaminación de los cursos de agua y de las aguas costeras llega en muchos casos a límites alarmantes. No mejor es la situación respecto a la eliminación de basuras y de la contaminación atmosférica.

Se comprenderá fácilmente la incidencia de estos factores desfavorables sobre las enfermedades transmisibles; la disminución de su morbilidad y mortalidad que se consigue con la aplicación de los programas de vacunación y de oportuno tratamiento. Por otra parte, este último, especialmente el hospitalario, representa cuantiosos gastos para los servicios de Salud y la utilización de personal y camas que podrían usarse para dar mejor atención a la población.

Por otra parte es política del Gobierno que el Servicio Nacional de Salud debe desprenderse de todas aquellas actividades que no tengan una relación directa con las acciones mismas de protección, fomento, recuperación y rehabilitación de la salud, como fueron, por ejemplo, la administración de propiedades y predios agrícolas o la administración de sociedades de valores bursátiles que, por imperio de la ley, se vendieron y su producto fue invertido en la construcción de hospitales y consultorios externos. Asimismo, el actual Gobierno considera que las actividades relacionadas con la producción y el abastecimiento de productos farmacéuticos, equipos e instrumental médico, anteojos, etc., debe quedar a cargo de organismos especializados y vinculados íntimamente con la organización de la economía nacional, que tengan la responsabilidad de la industrialización y distribución de dichos productos. Para este fin, se está estudiando la creación de corporaciones de producción farmacéutica y de distribución de estos productos con la participación financiera de todos los sectores previsionales interesados en mejorar las condiciones de salud de sus afiliados. Es así como el Estado se preocupará preferentemente de obtener la racionalización de la produeción de medicamentos y de los productos biológicos a fin de que la comunidad disponga de ellos en cantidad adecuada y a precios razonables ampliando a todo el pueblo los beneticios del Formulario Nacional. 


$$
-560-
$$

Todas las acciones señaladas no serán susceptibles de extensión si no se dispone de recursos humanos en cantidad suficiente y con la preparación técnica que corresponda a las necesidades nacionales y de distribución territorial adecuada, evitando su concentración desproporcionada en los grandes núcleos urbanos. Para ello, será necesario una acción coordinacia con las Universidades, los Colegios y Agrupaciones Profesionales con los cuales el Gobierno desea mantener cordiales relaciones y contar con su importante e imprescindible colaboración. Será, pues, indispensable, profundizar los estudios iniciados respecto a los recursos humanos en salud y su utilización con la participación de todas las Instituciones interesadas. El Gobierno da especial énfasis en esta política de un mejor aprovechamiento de los recursos humanos, que debe traducirse en una significativa elevación de la calidad de la atención médica a la población, a la estrecha vinculación entre el Servicio Nacional de Salud y las Facultades de Medicina, Odontología y Farmacia de las diferentes Universidades del país. En el presente año, se han concertado diversos convenios docente-asistenciales cuyas proyecciones se extienden a lo largo de todo el país y que permitirán por una parte un substancial aumento de la formación de profesionales nuevos y por otra, un adecuado perfeccionamiento en servicio, de los funcionarios y trabajadores de la Salud en general.

Estas acciones irán acompañadas de la aplicación de una política de personal que contemple justas remuneraciones de acuerdo a sus funciones y responsabilidades.

Debe mencionarse, también, el papel desempeñado durante el ejercicio del actual Gobierno por los Voluntarios de la Salud, provenientes de las Poblaciones, Asentamientos, Sindicatos y Organizaciones Comunitarias, los cuales han llevado su labor hasta los iugares más alejados y desamparados, debiendo especialmente mencionarse el inmenso esfuerzo y la cálida acogida que tuvieron los integrantes del Tren de la Salud que recorrió una parte importante del territorio nacional dando atención médica y dental a la población de extensos sectores no cubiertos hasta ahora.

El análisis de los problemas señalados en los párrafos precedentes, nos lleva a la conclusión de que se requerirá un esfuerzo mancomunado de toda la población, del Gobierno y de los Trabajadores de la Salucl que demandará una acción persistente y continuada sin la cual no será posible corregir los factores que influyen desfavorablemente sobre la salud. Sin embargo, como se destaca anteriormente, no será posible mejorar en forma real los niveles de salud de la población, si no se cambia previamente la infraestructura económico-social del país, se corrijan las actuales relaciones sociales de la producción, se libere la economía de su dependencia y su estancamiento y se consiga así elevar substancialmente los niveles de desarrollo del país y de vida y bienestar de todos los chilenos.

Lo anterior, sin embargo, no significa que no sea posible tomar medidas de urgencia, dentro de los actuales recursos disponibles, que permitan modificar situaciones predominantes que inciden desfavorablemente sobre la salud de las comunidades. El Gobierno así lo ha comprendido y previo un rápido estudio de la situación, ha puesto en marcha desde fines de Diciembre de 1970, una serie de medidas entre las que podemos señalar el aumento masivo de la distribución de leche para alcanzar a toda la población de niños menores de 15 años 
y a las madres gestantes y lactantes; el combate a las diarreas estivales de la infancia; la campaña de vacunación antipolio y otras y la extensión de la atención dental especialmente a las poblaciones suburbanas. Asimismo, se iniciaron de inmediato los estudios para acciones a más largo plazo para solucionar en forma definitiva el problema de la disposición de basuras y para formular un plan nacional de alimentación y nutrición.

Estos grandes lineamientos de la política nacional de salud deberán realizarse dentro del contexto de la política económica y social del Gobierno, lo que presupone una cuidadosa planificación que debe considerar, además, todos los factores que inciden directa o indirectamente sobre el nivel de salud de la población, incluyendo las situaciones de emergencia y las catástrofes que con cierta periodicidad afectan a nuestro país. En una palabra, el Plan Nacional de Salud, que está en proceso de formulación, será parte del Plan Nacional de Desarrollo Económico y Social.

\section{2.- PLANIFICACION DE LA SALUd.}

El Gobierno ha entendido que la planificación de las actividades de salud es uno de los requisitos indispensables para actuar armónicamente sobre todos los factores que inciden en los bajos índices de salud que presenta la población, especialmente las grandes masas afectadas por los deficientes niveles de vida. La acción simultánea sobre todos estos factores y el cambio estructural que con ello se persigue obligan a la formulación del plan de salud en estrecha vinculación con los planes de los demás sectores económicos y sociales, para supeditarse así a los grandes objetivos del desarrollo nacional.

ODEPLAN ha propuesto una estructuración para las actividades de planificación de todos los sectores con el ánimo de uniformar el proceso y hacerlo más convergente con los propósitos señalados. El Consejo Nacional Consultivo de Salud creado en la Ley $N^{\circ} 16.781$ se ampliará para transformarlo en un Consejo de Desarrollo del Sector Salud que impulse la política sectorial en el proceso del desarrollo nacional. Se está estructurando una Oficina de Planificación y Presupuesto en el Ministerio de Salud Pública para promover y coordinar la formulación de los planes y proyectos que está realizando el Sector. Al mismo tiempo, se está organizando Oficinas de Programación y Proyectos para efectuar la misma tarea en los Servicios e Instituciones respectivas.

La Oficina de Planeamiento del Servicio Nacional de Salud, que tiene existencia anterior a las medidas enunciadas, ha realizado diversas tareas en el período que corresponde al actual Gobierno. Estas incluyen la formulación del Plan del SNS. para 1971, y diversos estudios relacionados con el financiamiento del Servicio Nacional de Salud, con la distribución futura de las horas médicas y con la ampliación de la política del Gobierno. 


\section{3.- PROGRAMA DE MEJORAMIENTO DE LA ADMINISTRACION}

Con el objeto de aumentar la eficiencia de los Servicios se están impulsando diversas medidas que agilicen los acciones de salud contempladas en el Programa de la Unidad Popular, entre las cuales se destacan las siguientes:

a) La eliminación de las trabas burocráticas que impidan o dificulten la atención médica.

b) La paulatina supresión del pago de los medicamentos y exámenes en los hospitales.

c) La coordinación de todos los recursos que actualmente se destinan a salud tendiente a su mejor utilización para obtener un mejor rendimiento de la capacidad instalada.

d) El control, en colaboración con el Ministerio de Economia, de la producción y distribución de artículos farmacéuticos. Se tiende a crear un sistema de producción y abastecimiento sectorial por medio de una Corporación de Producción y otra de Abastecimiento.

e) La planificación de las actividades para asegurar el cumplimiento de la política de salud, preparando de este modo el camino para la integración de los servicios del sector.

f) La democratización de los servicios, llevando a los trabajadores de la salud y a la comunidad en general a los niveles de decisión en salud. Se trata de hacer efectiva, a nivel administrativo, la democracia que existe a nivel político. Constituye, pues, un perfeccionamiento de nuestra institucionalidad. Se constituirán, en todos los niveles de salud y en todas las instituciones, Consejos Directivos, que tendrán a su cargo la dirección de los establecimientos, los servicios y las estructuras centrales. Estos consejos, estarán formados por trabajadores de la salud en su más amplia concepción y representantes de la comunidad y sin per. juicio de las funciones y responsabilidades que les competen a los Jefes de Servicios y a los Directores de Hospital compartirán con ellos la responsabilidad de la administración. Las remociones, traslados, ascensos, etc., se regirán por las actuales disposiciones administrativas y legales, respetándose la idoneidad técnica, los concursos y la carrera funcionaria. La democratización se hará por etapas, como un proceso, para ir a la modificación estructural y deberá constituir la principal herramienta de la política del Gobierno Popular para elevar la eficiencia al Servicio Nacional de Salud.

Estos Consejos, juntamente con profundizar y desarrollar nuestra democracia, permitirán que nuestras estructuras de salud se adecúen al desarrollo de la ciencia médica contemporánea, en la cue ya el individuo ha sido superado por el equipo. También estos Consejos abrirán el cauce a las iniciativas creadoras de las masas. Solamente mediante ellos podremos mejorar la administración local haciéndola más eficiente, descentralizada y simple, evitando derroche de recursos, su mal aprovechamiento, la pérdida de instrumental, ropa, víveres, etc. 


\section{4.- SERVICIO NACIONAL DE SALUD.}

\section{1.- LOS PROBLEMAS EN EL CAMPO DEL FOMENTO DE LA SALUD.}

Es en el ámbito del fomento de la salud donde el programa de Gobierno ha obtenido los logros más visibles y los avances en mayor profundidad en relación con el propósito de hacer del niño el único priviliegiado de Chile. En torno al bienestar familiar y social operan los servicios de salud materno-infantil, de protección al menor en situación irregular, de alimentación y nutrición y de salud mental.

El $60 \%$ de la población del país lo constituyen madres y niños que, a su vez, forman el grupo más vulnerable a las condiciones del subdesarrollo económico y social del país. Los riesgos de morir de las madres y de los niños son aún muy elevados. La mortalidad infantil que en 1970 fue de 77,8 por mil, todavía está por encima de límites aceptables. De los menores de un año fallece un $38 \%$ por enfermedades respiratorias, seguida en importancia por las causadas por los riesgos perinatales $(22 \%)$ y por diarreas infantiles, con el $16 \%$ de las defunciones.

Aunque el $80 \%$ de las madres reciben atención profesional del parto, las defunciones asociadas al embarazo, parto y puerperio siguen siendo elevadas y condicionadas, en gran medida, por la inadecuada supervisión técnica. A esto se agrega el hecho de que una tercera parte de la mortalidad materna es debida a abortos por cuya causa se hospitalizan alrededor de $\mathbf{5 0 . 0 0 0}$ mujeres al año en el país.

Aunque la disponibilidad de proteínas y las calorías per cápita son adecuadas, su distribución poblacional dista mucho de ser satisfactoria y responde al tipo de estructura social y económica clasista del país. La desnutrición, afecta gravemente a los niños de los sectores proletarios, impidiendo en ellos el desarrollo del potencial genético de la raza con los ya bien conocidos efectos negativos sobre el crecimiento físico y probablemente sobre el desarrollo mental. Un 15\% de los lactantes inscritos en los consultorios distritales presenta grados variables de desnutrición y un $66 \%$ de los ingresos a servicios hospitalarios presenta déficit pondoestatural. De todo ello, se desprende que la desnutrición aparece como uno de los factores principales que condicionan el riesgo de enfermar y de morir. En este último sentido, las diarreas estivales y los trastornos respiratorios agudos del lactante, se ven considerablemente agravados por la desnutrición. Del mismo modo la desnutrición afecta el curso del embarazo y está asociada con el bajo peso del nacimiento y con la lactancia insuficiente.

Otro serio problema es el del menor en situación irregular. Hasta ahora se ha insistido más en el "niño problema" y se ha olvidado el fomento de la "regularidad". Con todo, la ausencia de una política y la inexistencia de datos objetivos que permitan conocer la magnitud del problema, explican la ausencia de programas coherentes para satisfacer la demanda de servicios para el niño impedido y su consecuente rehabilitación. Los problemas emergidos de los diferentes establecimientos son efectos directos de la falla de organicidad de una acción. 
Tampoco la salud mental ha recibido la atención necesaria. El ámbito de su acción está limitado a la acción manicomial y sólo existen esfuerzos aislados en el terreno de la psiquiatría comunitaria y en relación con el alcoholismo.

Los problemas señalados han movido a las autoridades de Gobierno a tomar las medidas más urgentes que se enumeran a continuación:

a) Expansión presupuestaria en relación con las actividades de fomento de la salud para $19 \% 1$.

Tradicionalmente las actividades de fomento nunca sobrepasan el $23 \%$ o el $24 \%$ del presupuesto operacional de Salud. El Gobierno expandió el presupuesto de fomento en $\mathrm{E}^{0} 380.000 .000$, lo que representa un $13 \%$ adicional, con lo cual estos recursos constituyen hoy más de un tercio del presupuesto de operación del Servicio Nacional de Salud. Con estos recursos, se abordarán las acciones que requieren los problemas señalados anteriormente.

\section{b) Campaña estival contra las diarreas infantiles.}

En la campaña estival contra las diarreas infantiles se fijó como objetivo disminuir el número de defunciones de menores de un año por esta causa en un $30 \%$. Durante los meses de Enero y Febrero se produjo una reducción de 420 casos de las defunciones de menores de un año por las causas señaladas, lo cual representa un importante ahorro de vidas con respecto a los años anteriores y un logro de trascendencia internacional. En algunas zonas estos descensos alcanzaron cifras que sobrepasan el $60 \%$ de disminución de las muertes en este rubro. Estos logros fueron obtenidos redistribuyendo los recursos habituales, además del trabajo voluntario y la participación de la comunidad organizada.

Merece destacarse el esfuerzo de enfermería para esta campaña, inventariando los recursos para las acciones de emergencia y el aumento de la demanda y al mismo tiempo dictando normas especiales para la atención de las diarreas agudas del lactante.

\section{c) Distribución de leche.}

Con una campaña inicial del Plan Nacional de Leche se materializó aquella medida anunciada por el Supremo Gobierno de otorgar medio litro de leche diario a todo niño chileno. Para estos efectos, se designó una Comisión Ejecutiva, la que junto con representantes de instituciones sanitarias, educacionales y del sector económico formularon y pusieron en marcha un ambicioso plan que contemplaba el abastecimiento de leche a las madres y a los menores de 15 años. La orientación general del plan fue la de universalizar el derecho a una adecuada alimentación, suplementando la dieta familiar con el aporte calórico proteico mínimo, otorgando este derecho gratuita y oportunamente.

El plan significó abastecer de leche en polvo con adecuado contenido graso a todos los beneficiarios mediante dos canales principales, fuera de los saldos de 1970: 
a) La producción nacional que oportó inicialmente 10 millones de kilos y que se espera aumente en 9 millones más este año, y

b) La importación de 30 millones de kilos del mercado internacional. La distribución se ha realizado a través de los servicios materno-infantiles de las instituciones de servicio público y semipúblico, con respecto a la población de embarazadas, nodrizas, y menores de 6 años. Para los escolares la distribución está a cargo de la Junta Nacional de Auxilio Escolar y Becas.

En el curso del primer trimestre de 1971 se han distribuido a través de las instituciones, 12 millones de kilos de leche en polvo cumpliendo, así, con las metas del programa. El número de beneficiarios ha aumentado en un $28 \%$ y la cantidad de leche distribuida en un $32 \%$. Para el resto del año, este aumento ha sido programado en un $300 \%$. Cabe hacer notar que este incremento se ha manifestado especialmente en los preescolares y embarazadas, ya que los lactantes tenían prácticamente una cobertura total.

Tanto en el programa de distribución de leche como en el de las diarreas estivales, la organización de actividades educativas fue de gran importancia. Se elaboraron normas especiales para guiar el trabajo del personal de los servicios, así como el de los voluntarios, a quienes se capacitó especialmente. Se preparó material educativo para el público y el personal; se promovieron reuniones informativas y se dio amplia publicidad a estos programas por medio de la prensa, la radio, la TV y las revistas.

\section{d) Expansión de los programas materno-infantiles.}

El Gobierno se propone expandir de un modo especial los programas materno-infantiles poniendo en ejecución el "Programa de Extensión de Servicios de Salud Materno-Infantil y Bienestar Familiar" para el cuadrienio 1972-75, para el cual se contará con la colaboración de la Organización Panamericana de la Salud.

La política general de expansión de los programas materno-infantiles contempla el ataque conjunto a todas las condiciones que hagan posible la elevación del nivel de vida de la población a beneficiar dentro del marco de una política integral de salud. Se estima indispensable la universalización de los servicios correspondientes, que tendría su expresión definitiva a través de un Servicio Unico de Salud, responsable de proporcionar atención igualitaria, integral, sectorizada, humana y oportuna con especial énfasis en la atención ambulatoria y en forma preferente en las comunidades rurales y urbano-marginales. Todas estas acciones están concebidas en el marco de un sistema nacional de regionalización asistencial y docente. Será necesario contemplar aquellas medidas que hagan más racional el uso de los servicios entre las cuales se incluye el adiestramiento de su personal, la investigación científica, la participación democrática de todos los trabajadores de la salud, la acción conjunta con los elementos organizados de la comunidad, etc.

Será particularmente importante el enfoque multidisciplinario que se dé a los programas materno-infantiles, en particular la coordinación con otros Organismos y en especial con el Ministerio de Protección a la Familia, de próxima creación. 
Se espera llevar la cobertura de los servicios al $90 \%$ de la población femenina del país en los principales aspectos de la salud de la mujer, considerando la prioridad de la atención ambulatoria en los grupos de población donde los problemas de salud pertinentes sean mayores. Se pondrá acento en el mayor riesgo del período perinatal y se dará el debido desarrollo a la Política de Población, dentro de la cual se contemplará y se facilitará, a toda mujer que lo solicite, el derecho para que planifique el número y la oportunidad con que tendrá sus hijos. Esta nueva faceta de la política de salud del Gobierno, tiene como fin reducir ciertos riesgos obstétricos y perinatales y contribuir a eliminar el aborto provocado ilegalmente, sin excluir la posible legalización del mismo.

La protección de lactantes y de preescolares será la llave maestra de la protección infantil, considerada como un proceso único de acciones preventivas y curativas de iniciación precoz, regular y periódica, con especial énfasis en el cuidado del crecimiento y desarrollo, dando prioridad al recién nacido, al prematuro y al desnutrido.

Se estima imperativa la cobertura del $90 \%$ de los niños menores de 6 años, dando preferencia a la prevención de las enfermedades transmisibles y los accidentes, la reducción de las muertes por enfermedades respiratorias, diarreas estivales y afecciones perinatales.

La vinculación de estos problemas a la condiciones culturales y económico-sociales obligará a considerar la coordinación necesaria para el desarrollo de programas conjuntos con otras entidades tales como la Junta Nacional de Jardines Infantiles y otras eventuales dependencias del Ministerio de Protección a la Familia y que permitan actuar con la comunidad. En el caso de los escolares, se actuará reformulando, con el Ministerio de Educación, una política que permita obrar sobre este grupo de la población, articulando los recursos humanos y materiales disponibles e introduciendo la participación de maestros, centros de padres y a los mismos educandos.

Según corresponda, se seguirá fortaleciendo el funcionamiento de centros especializados de cuidado de la salud, de orientación vocacional y hacia la vida familiar del adolescente, así como de rehabilitación del niño impedido a base de la labor que debe realizar en ellos un equipo profesional multidisciplinario. Un aspecto de este programa lo constituye un proyecto de creación de un Consultorio Integral Distrital de Salud y Protección Familiar para Valparaíso, cuya acción se ejercerá en torno a la familia a la cual se prestará atención médica y dental y por su intermedio se extenderán las acciones al mejoramiento de las condiciones sanitarias donde viven las familias y a la comunidad, brindando a la población facilidades recreativas, jardines infantiles, sala cuna, orientación familiar, higiene mental, etc. Será un Centro Modelo para adiestrar, en torno a las prácticas de acción comunitaria e investigar sobre estos problemas.

\section{e) Política alimentaria y nutricional.}

La inadecuada alimentación y la desnutrición limitan las posibilidades para que sectores importantes de la población chilena alcancen el buen nivel de salud necesario para la ejecución de las tareas que plantea el desarrollo económico y social de la Nación. Muchas medidas que van a mejorar en definitiva el estado nutricional de la población no 
le son propias a Salud. Pero, como el mal estado nutritivo provoca un bajo rendimiento en las cuantiosas inversiones que se hacen el el sector, a Salud le corresponde asumir el liderazgo en la promoción de la planificación intersectorial que derive en la formación de una Política Alimentaria y Nutricional (PAN).

La Política Alimentaria y Nutricional es un conjunto de recomendaciones que llevan a armonizar o a modificar las políticas sectoriales (Agricultura y Pesca, Industria, Economía, Educación, Salud, Comercio Exterior, etc.), para conseguir el doble objetivo de mejorar el estado nutritivo de la población y satisfacer las demandas del abastecimiento alimentario.

Hay que considerar que aparte y además de cualquiera consideración de tipo económico o sanitario, el cumplimiento de estos dos objetivos constituyen una legítima aspiración de los pueblos y son en sí metas del desarrollo.

La desnutrición y la subnutrición obedecen a causas que arrancan del bajo nivel de vida al que está sometida una importante proporción de la población chilena y que siempre se asocia al inadecuado saneamiento ambiental, hacinamiento, ilegitimidad, falta de conocimiento de las madres sobre el cuidado de los niños, bajos salarios y altos precios de los alimentos protectores. En consecuencia, medidas tecnicistas, puramente nutricionales, no serían nunca capaces, por sí solas, de corregir la alta prevalencia de la subnutrición y la desnutrición, si no se logra, simultáneamente, salir del subdesarrollo económico y social que afecta al país.

A Salud le cabe la importante tarea de promover el buen estado nutritivo y de reducir las tasas de subnutrición y de desnutrición a través de medidas preventivas, curativas y de rehabilitación. Es de notar que los programas de promoción del buen estado nutritivo (la dación de leche, desayuno y almuerzo escolar y aquellos relacionados con la nueva ley de salas cunas y jardines infantiles), considerablemente ampliados por el presente Gobierno, constituyen una gran conquista social que pronto se verá reflejada en un marcado mejoramiento de la salud del niño chileno. Estos programas, por el enorme número de beneficiarios, significan una muy importante inversión, la que debe ser protegida a través de una administración. del más a.lto nivel.

\section{f) Política de Salud Mental.}

El Gobierno tiene especial interés en encontrar una solución definitiva e integral a los serios y dolorosos problemas que representan la salud mental para la población y que fundamentalmente afectan a los sectores proletarios y de menor ingreso.

Dentro de estas ideas se creó por Decreto, la Comisión Interministerial de Salud Mental por iniciativa personal del Presidente de la República, integrada por representantes técnicos de los Ministerios de Educación, Salud, Interior y Justicia. Esta Comisión, que se reúne periódicamente, realizó unas jornadas de Salud Mental en la semana del 12 de Enero pasado y cuyas conclusiones, avaladas por la participación multidisciplinaria de diferentes profesiones, han sido dadas a conocer a cada Ministerio, los cuales están realizando las labores específicas que les corresponde, en concordancia con la política recomendada. 
Suscintamente los problemas planteados se refieren a:

1.- Combate científico organizado al alcoholismo;

2.- Combate a la drogadicción, con participación activa de los organismos administrativos y de la juventud, representada por diferentes organizaciones de base;

3.- Humanización de la atención psiquiátrica, cambiando la tradicional atención cerrada por una atención comunitaria y abierta en la cual se dé una especial importancia a los familiares de los enfermos;

4.- Creación y organización de recursos humanos y de construcciones de establecimientos y talleres de laborterapia para la rehabilitación de los enfermos mentales.

\section{2.- PROTECCION DE LA SALUD}

\section{a) Inmunizaciones.}

Se realizó un programa de inmunización de emergencia contra la poliomielitis de la región Sur del país, realizándose 310.000 vacunaciones desde Concepción a Magallanes de niños de 3 meses a 6 años, lo que representa la cobertura del $30 \%$ de los niños de las edades señaladas.

Aprovechando la campaña de distribución de leche, se intensificó el programa general de vacunaciones lográndose un aumento del $10 \%$ de las vacunaciones totales en los primeros meses de 1971 en relación a años anteriores.

\section{b) Prevención de diarreas estivales.}

El Subdepartamento de Protección de la Salud tuvo una participación activa en la campaña de prevención de las diarreas estivales infantiles. La Sección Control de Alimentos cooperó efectuando un control de las cocinas de leche de los hospitales del país comprobándose una alta contaminación microbiana. Tanto en los hospitales como en las comunidades se hicieron demostraciones de la manera correcta de manipular la leche. Asimismo se está realizando un estricto control de la calidad de la leche en polvo que se entrega a la comunidad.

\section{c) Higiene del Ambiente.}

En esta materia, además de la colaboración fundamental prestada al Comité Interministerial que se ocupa del problema de basuras, el Servicio Nacional de Salud se preocupó de las instalaciones sanitarias, educación y control de los diversos campamentos de veraneo organizados por el Gobierno. Se reiniciaron las obras de 14 proyectos de agua potable en asentamientos de la CORA, en el Valle del Choapa, que se habían paralizado por falta de fondos y se continúan los proyectos en Diaguitas y Rivadavia (Valle de Elqui) y Caimanes, en Illapel. Se han instalado sistemas de cloración en 175 servicios de los 182 ya entregados a la población. Está en avanzado estado de estudio un proyecto para dotar de agua a 400 nuevas localidades mediante un nuevo contrato de préstamo que se gestionará con el BID 


\section{d) Higiene y Seguridad Industrial.}

Se ha concentrado especialmente, en la atención en los riesgos de silicosis, tóxicos cancerígenos, intoxicaciones por solventes y plomo. En Seguridad Industrial se ha programado el trabajo para el control de las industrias que presenten mayor riesgo, incluyendo vigilancia sobre calderas y autoclaves. La V Zona (Santiago) del SNS ha mantenido su acción de terreno para el control de la contaminación atmosférica y está dando término a un curso de auxiliares para estas labores. En Medicina del Trabajo se han continuado las pesquisas, prevención y control de enfermedades profesionales. El Instituto de Higiene del Trabajo y Contaminación Atmosférica del SNS ha colaborado en todas las acciones antes mencionadas además de la supervigilancia de la contaminación radioactiva de muestras de leche y aire.

e) Comisión Técnica para la disposición de basuras.

Ante la gravedad de la situación provocada por la falta total de recolección de basuras domiciliarias en numerosas poblaciones populares y su deficiente recolección en otras, situación que sólo en el gran Santiago afecta airrededor de 800.000 personas, con los agravantes que ello implica para la salud pública, el Supremo Gobierno ha procedido a dictar el Decreto $\mathrm{N}^{0} 20$, de 15 de Febrero de 1971, que crea la Comisión Técnica para la Disposición de Basuras, presidida por el Ministro de Salud. Esta Comisión dio lugar a la Subcomisión de Emergencia destinada fundamentalmente a poner en práctica planes de recolección de emergencia, eliminación de basurales, aplicación de insecticidas y raticidas y acciones de educación sanitaria a la población. Esta Subcomisión estimó que las condiciones ambientales en que se desenvuelven los habitantes de las poblaciones afectadas constituyen un verdadero estado de calamidad pública, razón por la cual fueron solicitados y acordados fondos por $\mathrm{E}^{\mathbf{0}} 3.000 .000$ para la inmediata ejecución de los planes elaborados a aplicar a través de la Oficina de Emergencia del Ministerio del Interior y una cantidad similar para la adouisición de bulldozers para la recolección. Se procedió, además, a la contratación de 80 vehículos destinados a normalizar la recolección de basuras.

Se encuentra también en trabajo la Subcomisión Técnica dispuesta por el Ministerio de Salud, en la que participan ingenieros de CORFO, Ministerio de Obras Públicas, Ejército, Universidad de Chile, SNS, I. Municipalidad de Santiago, con la asesoría de ingenieros de la Organización Panamericana de la Salud, con el objeto de entregar soluciones concretas y de fondo para resolver en definitiva un asunto que, como el de la disposición de las basuras, reviste una extraordinaria importancia para la salud pública, dado el creciente aumento de la población que alcanza caracteres explosivos en los grandes centros urbanos.

Puede afirmarse que por primera vez un Gobierno toma con la debida seriedad, para resolverlo, un problema ya crónico, creciente, que afecta $\tan$ negativamente las condiciones ambientales y de salud de la población, en especial, de la población de bajos ingresos.

\section{3.- RECUPERACION DE LA SALUD}

\section{a) Comisión Nacional del Cáncer.}

Dada la gravedad que está adquiriendo el Cáncer, la Comisión Nacional está preocupada de fijar las áreas prioritarias de la política de prevención y tratamiento que deberán iniciarse. Se han aumentado los 
elementos de tratamiento y diagnóstico de los 5 Centros Regionales de Cancerología (Antofagasta, Valparaíso, Santiago, Concepción y Valdivia) dándole especial importancia a los cánceres cérvico-uterino y de estómago.

Aunque la información disponible en Chile deja en claro que las neoplasias constituyen la tercera causa de muerte, con tendencia al ascenso, no es posible discernir con claridad una serie de aspectos necesarios para orientar la acción, distribuir los recursos, elegir los métodos, etc. Estos problemas serán dilucidados con la implantación de un Registro de Cáncer que se está llevando a cabo. Será una herramienta extremadamente útil para la investigación epidemiológica y clínica del cáncer, para organizar los programas de control y proceder a la auditoría médica, tan necesaria para resolver los factores que inciden en la aparición y manejo de los casos.

\section{b) Medicina Física y Rehabilitación.}

En materia de Medicina Física y Rehabilitación, la Comisión creada por la Ley 17.328 que permite la importación de vehículos especialmente adaptados para lisiados a un precio más bajo, ha tenido una ardua labor habiendo revisado alrededor de 1.500 solicitudes.

Considerando que el gasto en divisas que representa esta ley es muy elevado, el Ministerio tiene en estudio una modificación que permíta la libre internación de los dispositivos que permitan adaptar los vehículos nacionales para el uso de lisiados.

Con el objeto de poner a disposición de toda la población sin discriminaciones los beneficios de la especialidad se están ampliando los servicios para lo cual se ha llamado a concurso para promover 61 cargos de kinesiólogos y 21 terapeutas ocupacionales.

\section{c) Traumatología.}

Dada la alarmante y creciente tasa de accidentes que se registra en el país, la atención traumatológica día a día adquiere mayor importancia. Se ha elaborado un programa completo de dotación de instrumental para 30 servicios de esta especialidad en todo el país. Se han preparado normas generales para su funcionamiento y para estructurar un plan de becarios. Asimismo se ha dado énfasis para el mejoramiento de la atención de traumatizados en los Servicios de Urgencia.

\section{d) Atención de Beneficiarios del SERMENA.}

Para la mejor atención de los empleados beneficiarios de la Ley de Medicina Curativa (№ 16.781) del SERMENA en los hospitales del Servicio Nacional de Salud se han extendido los convenios de modo que mientras en Julio de 1970 sólo un $50 \%$ de los hospitales participaba en el sistema, en Marzo de 1971 prácticamente todos ellos (un 95\%) colaboran en la atención de los pacientes del SERMENA.

\section{e) Sección de Odontología.}

A cargo de la Sección estuvo la distribución a través del país, de 24 equipos portátiles y de 7 clínicas móviles para la atención del campesino y de 120 unidades y sillones dentales para reforzar la atención odontológica del niño, la madre y el adulto, en los sectores urbanos, suburbanos y rurales. 
Durante el verano se puso en operación el TREN DE I:A SALUD en coordinación con la Federación de Estudiantes de Chile y el Ministerio de Educación. En él actuaron 56 voluntarios médicos, dentistas, laboratoristas y farmacéuticos. Recorrió una extensa región del país y en lo que se refiere a odontología prestó 14.000 atenciones. Fue necesario reforzarlo, por parte del SNS en lo que se refiere a odontología, con 6 profesionales, 4 equipos portátiles, instrumental y material diverso.

La nueva promoción odontológica permitió la distribución de 130 cargos con 780 horas-días, especialmente para la atención de sectores rurales y poblaciones marginales.

En 96 localidades del país se reinició y se reexpandió el programa de fluoruración de los abastos de agua potable para la prevención de las caries dentarias.

Diversas medidas administrativas, y estudios técnicos y preparación de personal auxiliar y voluntario completaron la labor de la Sección de Odontología. Merece destacarse la creación de la Posta Dental del Hospital Barros Luco para la atención de urgencia nocturna en domingos y festivos. En el período 1970-71 se han efectuado 23.000 atenciones incluyendo 11.000 extracciones y 3.000 obturaciones.

Se han destinado y acondicionado para la atención ambulatoria, 6 buses con 25 dentistas los cuales han prestado atención en diversas poblaciones marginales del país.

\section{f) Sección Farmacia.}

Se inició un estudio para evaluar el consumo de marihuana en los Colegios y Escuelas del gran Santiago.

Se elaboró un informe para el Ministerio de Salud sobre los decomisos de cocaína enviados a esta Sección por los diferentes Juzgados del país.

Se estudiaron las modificaciones del Art. 11 del Reglamento de Productos que causan dependencia, en relación de la situación de los médicos veterinarios y odontólogos que prescriben sicotrópicos, lo que fue materializado mediante Decreto $N^{\circ} 63$ de 26 de Enero de 1971.

Se realizó un estudio de la modificación del Art. 21 del Reglamento de Estupefacientes, sobre el uso del recetario oficial para la prescripción de drogas que causan dependencia, lo que fue materializado mediante Decreto No 65 de 28 de Enero de 1971.

Se elaboró el proyecto reglamentario de la Ley 17.340 que creó el Colegio de Químico-Farmacéuticos de Chile.

Se revisaron los proyectos de Reglamentos sobre Industrias Químico-Farmacéutico, Alimentos de uso médico, Productos Farmacéuticos y Cosméticos.

\section{4.- CONTRATACION DE NUEVAS PROMOCIONES DE PROFESIONALES}

El SNS fijó una política de contrataciones de nuevas promociones de profesionales y otros grupos funcionarios utilizando antecedentes tales como las necesidades del Servicio en cuanto a más personal y 
también, preocupado por absorber parte de la cesantía técnica generada por la falta de coordinación entre las Escuelas y Universidades y las Instituciones empleadoras. Este propósito se logró al definir como promoción 1971 a aquellos profesionales y grupos técnicos de la salud que obtuvieron su título profesional durante los años 1969, 70 y 71 y que no habían ingresado aún al SNS.

La contratación de profesionales y otros grupos técnicos modifica substancialmente anteriores políticas del SNS: Contratará toda la oferta de promoción de profesionales, por el máximo de tiempo legalmente permitido, teniendo el compromiso de trabajo por horario completo. Agregará una asignación de monto proporcional a las dificuitades de trabajo y de acceso al lugar elegido, criterio que se aplicará también al puntaje que el profesional acumula durante su estadía en un lugar específico.

Los postulantes profesionales y técnicos a cargos en el SNS tienen la posibilidad de elegir el lugar de trabajo entre una gran cantidad de plazas, reservándose el SNS la selección de estas plazas según los intereses prioritarios de la atención médica. En aquellos casos donde el número de postulantes es mayor que el número de plazas, se otorgará prioridad a aquellos profesionales y técnicos que cumplan con los siguientes requisitos: a) calificaciones académicas; b) situaciones de arraigo familiar; c) trabajo realizado anteriormente en el lugar respectivo, en cualquier calidad (voluntario, auxiliar técnico, reemplazo, etc.)

El SNS fijó una distribución utilizando sólo dos indicadores: a) disponibilidades actuales de personal y b) la importancia relativa del daño de salud de la localidad respectiva. Con estos criterios dividió las prioridades en 4 grupos:

Primera prioridad: Zonas que tienen alto déficit de personal y alto daño de salud.

Segunda prioridad: Zonas que tienen alto déficit de personal y daño relativamente bajo de salud.

Tercera prioridad: Zonas que tienen alto daño de salud y poco déficit de personal.

Cuarta prioridad: Zonas que tienen poco daño de salud y poco déficit de personal.

Esta política se tradujo en el ofrecimiento de plazas nunca antes propuestas por el SNS.

Se crearon las siguientes plazas:

320 Médicos generales de zona.

20 Médicos becados primarios.

130 Dentistas.

12 Farmacéuticos.

308 Matronas.

160 Nutricionistas.

53 Educadoras de Párvulos.

130 Tecnólogos Médicos.

20 Terapeutas Ocupacionales.

61 Kinesiólogos. 
300 Enfermeras.

222 Asistentes Sociales.

24 Psicólogos.

15 Ingenieros.

9 Constructores Civiles.

44 Médicos Veterinarios.

1.100 Auxiliares de Enfermería.

40 Auxiliares de Laboratorio.

20 Educadores Sanitarios.

Estas mismas contrataciones, en 1970, fueron las siguientes:

150 Médicos Generales de Zona.

220 Enfermeras.

105 Matronas.

231 Asistentes Sociales.

55 Tecnólogos Médicos.

840 Auxiliares de Enfermería.

\section{5.- CONSTRUCCIONES Y REMODELACIONES DE ESTABLECIMIENTOS}

La Sección correspondiente del Subdepartamento de Recuperación de la Salud del Servicio Nacional de Salud, tiene a su cargo la programación técnica de las construcciones y remodelaciones de hospitales y consultorios, como asimismo el estudio de sus habilitaciones. El Subdepartamento de Arquitectura, la confección de proyectos y planos correspondientes a remodelaciones y reparaciones de las obras. La Sociedad Constructora de Establecimientos Hospitalarios, por su parte, la confección de proyectos y planos de los hospitales, consultorios y postas, que le encargan el Servicio Nacional de Salud u otras Instituciones del Sector Público, como igualmente la responsabilidad de su construcción.

El Subdepartamento de Recuperación del SNS, desde Noviembre de 1970 programó la habilitación, entre otros, de los nuevos Consultorios de los hospitales de La Serena y Copiapó, de las ampliaciones del Hospital de Vicuña, del nuevo Hospital de Santa Bárbara, del Servicio de Psiquiatría del Hospital de Temuco, de la ampliación del Consultorio y servicios administrativos de Valdivia, del Hospital de Los Muermos, con una inversión por este concepto, de $\mathrm{E}^{0} 1.660 .996,79$.

En cuanto a programas de construcciones y estudios especiales, programó la remodelación del Servicio de Obstetricia del Hospital de Arica. Estudió con las autoridades locales un plan completo para solucionar la situación hospitalaria de la Zona de Valparaíso, a lo que también se hace alusión más adelante. Estudió la adaptación del edificio de la ex Escuela de Agronomía de la Quinta Normal, para trasladar desde el Hospital San Juan de Dios, parte de los Servicios Administrativos e instalar un Laboratorio multidisciplinario, colaborando así con los planes de la Facultad de Medicina de la Universidad de Chile para ampliar su matrícula, y dejando mayor espacio en el hospital para aumentar sus prestaciones. 
Estudió un plan de emergencia para satisfacer la situación asistencial de Las Barrancas, que comprende la ampliación de los consultorios existentes, adaptación del Centro Comunitario Sara Gajardo y creación de servicio nocturno de ambulancias.

Estudió en el terreno un programa de construcciones y reparaciones de los distintos Servicios del Hospital Regional de Concepción.

Asimismo estudió en el terreno el grado de cumplimiento de las etapas de construcción y habilitación del nuevo Hospital de Angol, recientemente terminado, como también estudió y gräficó el sector del Hospital antiguo para que sea destinado a escuela de enseñanza básica.

\section{Subdepartamento de Arquitectura del SNS.}

Durante los últimos cuatro meses anteriores al 31 de Marzo, bajo la tuición del Subdepartamento, se dio término a un conjunto de obras por un valor de $\mathrm{E}^{0} 7.868 .910$ entre las que se incluyeron 3 nuevos consultorios externos en provincias, jardines infantiles anexos a algunos hospitales de Santiago y diferentes obras de ampliación y remodelación de diversas dependencias del SNS en el país.

A la fecha hay en ejecución obras por un valor de $\mathrm{E}^{0} 21.628 .065$, que contemplan ampliaciones, remodelaciones y trabajos diversos, en hospitales de provincias, consuitorios periféricos y otros establecimientos.

Para fundamentar un plan de nuevas construcciones, el Subdepartamento ha iniciado estudios de infraestructuras en diversas zonas del SNS, que contempla una inversión de E0 30.000 .000 a ser ejecutados por la Sociedad Constructora de Establecimientos Hospitalarios en un plazo de tres años.

Por otra parte, el Subdepartamento, ha continuado la producción de las "Normas Arquitectónicas" para los hospitales chilenos, habiéndose ya entregado las "Normas Provisionales" para los servicios de Maternidad y Centros de Recién Nacidos, expuestos a altos riesgos o sometidos a tratamiento intensivo.

\section{Sociedad Constructora de Establecimientos Hospitalarios.}

Esta Sociedad, organismo dependiente del Ministerio de Salud Pública, mantuvo regular e ininterrumpidamente durante 1970 su labor de construcción de los establecimientos de salud para el sector público. Se atendieron de este modo, las necesidades del Servicio Nacional de Salud, la ampliación del Hospital de la Fuerza Aérea de Chile en Santiago y la construcción del Hospital Regional del SERMENA de Valparaíso.

Por otra parte, la Ley 16.781 cbliga al SERMENA a invertir el 5\% de los recursos de la Medicina Curativa en ampliar la capacidad de hospitalización del Servicio Nacional de Salud para que pueda satisfacer la demanda de atención de los beneficiarios de dicha ley. En cumplimiento de esta disposición se han hecho ampliaciones en los Hospitales San José, Barros Luco-Trudeau, Exequiel González Cortés, en Santiago y San Luis, de Buin. 
Particular esfuerzo se ha destinado a perfeccionar la elaboración de los proyectos arquitectónicos, desarrollando conceptos y normas de racionalización, standardización, modulación y otros, consiguiendo de este modo apreciables economías.

Durante 1970 la Sociedad dio término a obras con una superficie edificada de $27.932 \mathrm{~m}^{2}$ que comprenden edificios y obras diversas de 12 hospitales, 2 consuitorios externos y 75 postas rurales.

Para 1971 figuran numerosos proyectos con el ánimo de extender e intensificar las construcciones hospitalarias a lo largo del país. Se consultan obras por un total de $164.218 \mathrm{~m}^{2}$.

Entre los proyectos especiales se contempla la construcción de un Consultorio Integral Distrital Modelo para Valparaíso, al cual se hace referencia en otra parte de este Mensaje. Este Consultorio Integral, que incluye consultorio médico y dental y un centro familiar comunal tendrá un costo de $\mathrm{E}^{\mathrm{o}} 14.500 .000$ y servirá de modelo para extender este tipo de servicio a todo el país.

\section{SERVICIO MEDICO NACIONAL DE EMPLEADOS}

El SERMENA, institución que centraliza las atenciones médicas del Estado en el régimen de empleados, ha continuado dinamizando la aplicación de la Ley 16.781 de Medicina Curativa que beneficia a una población de dos millones de personas. Numerosos convenios con diversas instituciones han permitido ampliar los beneficios de la ley al extenderlos a mayor población. El Gobierno ha elevado el aporte al Fondo de Asistencia Médica para bonificar el $70 \%$ de la prestación médica y el $50 \%$ de las intervenciones quirúrgicas eliminándose el pago del $10 \%$ que debía efectuar el empleado en el momento de solicitar una atención quirúrgica, obstétrica o similar. Al mismo tiempo, se han otorgado beneficios a personas de escasos recursos para adquirir marcapasos y otros elementos ortopédicos vitales para enfermos del corazón; así como audífonos, medicamentos, etc.

Diversas medidas legales y administrativas como ampliaciones horarias, incorporación de representantes gremiales a la Comisión Central de Medicina Preventiva, ampliaciones de atenciones materno-infantiles, etc., son indicaciones del aumento de los beneficios otorgados. En grandes líneas estos beneficios pueden resumirse en las acciones siguientes:

Programa de leche. - En 1970 se distribuyeron, desde el mes de Agosto, 670 mil Kgs. de leche habiéndose programado para el presente año un total de 5 millones de kilos, lo cual representa un aumento de casi ocho veces el programa del año anterior. Diversas instituciones participan en el programa de distribución entre las cuales están los servicios de bienestar del Ministerio de la Vivienda, de la Compañía de Acero del Pacífico, de Transportes Colectivos del Estado y numerosas Farmacias particulares de Santiago.

Atención médica y dental periférica.- Para 1971 se programa la creación de unidades periféricas integrales para la atención médica, dental, materno-infantil, entrega de leche, etc. Carácter de extrema urgencia tiene el plan dental por el elevado número de caries en la población, así ccmo el de las enfermedades de las encías y los trastornos de 
la mala implantación de los dientes especialmente en los niños. Para este efecto se dispone la ampliación de las horas dentales diarias y la creación, entre otras medidas, de un Centro Odontológico para la atención especializada.

Con la llegada al país de 50 sillones dentales se ampliará considerablemente la atención de los beneficiarios de este Servicio.

Ampliaciones regionales, de equipos y delegaciones.-Como forma de agilizar y jerarquizar debidamente algunas dependencias del Servicio, hecho que redundará en beneficio de sus imponentes, se ha aprobado recientemente la creación del Regional de Aconcagua, con sede en San Felipe.

Del mismo modo se ha acordado la creación de los equipos médicos de Viña del Mar, Melipilla y Nueva Imperial.

Igualmente, se contempla la próxima creación de Regionales, equipos y delegaciones en diversas zonas del país, para llevar atención médico-funcionaria a los imponentes.

Venta de órdenes de atención-cheque por Tesorería.-Se pondrá en práctica, próximamente, un convenio suscrito entre el Servicio Médico Nacional de Empleados y la Tesorería General de la República, que permitirá la venta de órdenes de atención-cheque en todas las Tesorerías Comunales del país, donde no existan dependencias del Servicio, lo que permitirá poner al alcance de los beneficiarios las atenciones médicas pertinentes.

Descentralización en el pago de subsidios de reposo.- Como forma de acelerar y lograr el pago de los subsidios de reposo se estableció en las leyes $6.174,11.462$ y 16.781 , se han dado instrucciones para la liquidación y pago de los mismos, en los diversos Regionales del país, medida que redundará en directo beneficio de los imponentes, terminando con los problemas derivados de los atrasos en los pagos respectivos.

Adquisición de una Bomba de Cobalto.- Se ha obtenido el acuerdo del $\mathrm{H}$. Consejo Asesor para adquirir una Bomba de Cobalto Teratrón 80, destinada al tratamiento del cáncer. El Servicio Médico Nacional de Empleados y la Universidad de Chile, se han integrado en una Comisión que está estudiando la posibilidad de establecer un servicio único a nivel nacional en el tratamiento del cáncer a fin de dar con este instrumento, atención gratuita a los afiliados. Integrarán, además, esta Comisión representantes del Departamento de Energía Atómica, que proporcionará la asistencia técnica correspondiente.

Adquisición de Acciones del Laboratorio Chile.-Se ha facultado al SERMENA para invertir hasta la suma de $\mathrm{E}^{0} 5.000 .000$ en la adquisición de valores del Laboratorio Chile S.A.

Ampliación Regional Valparaíso.- Próximamente serán inauguradas las ampliaciones del Regional Valparaíso que permitirán una mejor atención dental, materno-infantil y administrativa en esa ciudad. En estas ampliaciones serán instaladas 16 clínicas dentales con equipos recientemente llegados al país. 


\section{7.- POLLA CHILENA DE BENEFICENCIA}

Entre el 8 de Noviembre de 1970 y el 14 de Marzo de 1971, la Polla ha realizado 10 sorteos con una venta total de Eo 142.827 .525 que dejaron una utilidad de $\mathrm{E}^{0} 24.209 .432,43$ y produjeron un ingreso fiscal por impuestos ascendente a $\mathrm{E}^{0} \mathbf{5 . 5 7 1 . 4 8 6 , 4 6}$. Las instituciones beneficiadas con estos sorteos fueron la Corporación de Servicios Habitacionales, las Universidacles, la Sociedad Constructora de Estajlecimientos Hospitalarios, el Ropero del Pueblo, el Servicio Nacional de Salud y los Cuerpos de Bomberos del país.

\section{8.- PROGRAMAS DE COLABORACION INTTRNACIONAL}

Dertro de la política tradicional chilena de mantener la más estrecha colaboración con todos los países y que el actual Gobierno ha reafirmado y extendido, el Ministerio de Salud Pública ha buscado la cooperación y asistencia con los Organismos Internacionales y Agencias Especializadas de las Naciones Unidas y muy especialmente con las Organizaciones Panamericana y Mundial de la Salud (OPS/OMS), con el Fondo de las Naciones Unidas para la Infancia (UNICEF), con el Programa de las Naciones Unidas para el Desarrollo (PNUD), con la Organización para la Alimentación y Agricultura (FAO) y con el Programa Mundial de Alimentos (PMA).

Para mantener la debida coorcinación de sus programas internacionales con otros Ministerios y reparticiones, el Ministerio de Salud Pública ha estado en permanente contacto con la Comisión Nacional de Investigaciones Científicas y Tecnológicas (CONICYT).

La OPS/OMS presta asistencia al Gobierno de Chile en 31 programas relacionados con el control de las enfermedades transmisibles, el saneamiento del medio, los servicios de salud, la investigación de recursos humanos, el desarrollo de los servicios de enfermería y de salud materno-infantil, el adiestramiento de investigadores en los problemas de nutrición, la salud mental, el cáncer, la higiene del trabajo y la rehabilitación, además de numerosos programas de ayuda a instituciones docentes.

La OPS/OMS concede gran importancia al adiestramiento del personal, razón por la cual adjudica un número importante de becas a expertos nacionales para perfeccionamiento en el extranjero.

La asistencia de la OPS/OMS en 1971 al Gobiemo de Chile asciencie a US\$ 626.082 .

Entre los proyectos que el Gobierno Popular ha estudiado a fondo podemos citar la modernización del Instituto Bacteriológico y de su planta de penicilina; la extensión del programa de asistencia alimentaria a los hospitales del SNS que ha permitido derivar parte de los recursos economizados a la construcción de postas médicas rurales; un estudio para la industrialización del hidrolizado de merluza que permitirá aumentar sustancialmente la disponibilidad de proteína animal, beneficiando también a la Facultad de Medicina de la Universidad de Chile; la modernización y humanización de la atención de los enfermos mentales; el control de las principales zoonosis, problema cuyas consecuencias no sólo tiene incidencia en la salud sino que contribuyen a 
disminuir la posibilidad de proteínas animales; la extensión de la atención dental; la determinación de una política nacional de alimentación y nutrición; el incremento de las actividades de saneamiento ambiental, especialmente en lo que se refiere al control de la polución y a los programas de agua rural y de disposición de basuras; la extensión de los programas de salud materno-infantil en estrecha coordinación con el Ministerio de la Familia, de próxima creación; el estudio de un plan sexenal para la instalación y desarrollo de servicios asistenciales que incluye nuevos consultorios integrales y la construcción y renovación de varios hospitales para que sirvan a la atención y a la docencia; el desarrollo de un sistema de información por medio de técnicas de computación electrónica que beneficie conjuntamente al MSP y a la Facultad de Medicina, y finalmente se cuenta con la colaboración de la OPS/ OMS para la creación de un sistema sectorial de planificación de la salud, así para como la organización de las unidades respectivas.

Reconocimiento merece el convenio celebrado con el Gobierno de Suecia por medio del cual éste dona materiales e instrumental a 46 clínicas materno-infantiles dentro del programa de planificación de la familia. Diversos Gobiernos americanos y europeos han contribuido a la formación de personal profesional y técnico por medio de becas y expertos para diversos programas en estudio y en ejecución. 